\title{
Indian Society of Gastroenterology consensus statements on Crohn's disease in India
}

\author{
Balakrishnan S. Ramakrishna • Govind K. Makharia • \\ Vineet Ahuja - Uday C. Ghoshal • Venkataraman Jayanthi • \\ Benjamin Perakath • Philip Abraham - Deepak K. Bhasin • \\ Shobna J. Bhatia • Gourdas Choudhuri - Sunil Dadhich • \\ Devendra Desai • Bhaba Dev Goswami - Sanjeev K. Issar • \\ Ajay K. Jain • Rakesh Kochhar • Goundappa Loganathan • \\ Sri Prakash Misra • C. Ganesh Pai • Sujoy Pal • Mathew Philip • \\ Anna Pulimood • Amarender S. Puri • Gautam Ray • Shivaram P. Singh • Ajit Sood • \\ Venkatraman Subramanian • Indian Society of Gastroenterology Task Force \\ on Inflammatory Bowel Diseases
}

Received: 29 January 2015 / Accepted: 29 January 2015 / Published online: 14 March 2015

(C) Indian Society of Gastroenterology 2015

B. S. Ramakrishna $(\bowtie) \cdot$ B. Perakath $\cdot$ A. Pulimood

Christian Medical College, Vellore 632 004, India

e-mail:wurama@hotmail.com

G. K. Makharia $\cdot$ V. Ahuja $\cdot$ S. Pal

All India Institute of Medical Sciences, New Delhi 110 029, India

P. Abraham • D. Desai

P D Hinduja National Hospital, Mumbai 400 016, India

U. C. Ghoshal · G. Choudhuri

Sanjay Gandhi Postgraduate Institute of Medical Sciences,

Lucknow 226 014, India

V. Jayanthi

Global Health City, Chennai 600 100, India

D. K. Bhasin • R. Kochhar

Postgraduate Institute of Medical Education and Research,

Chandigarh 160 012, India

S. J. Bhatia

Seth G S Medical College and KEM Hospital, Mumbai 400 012, India

S. Dadhich

S N Medical College, Jodhpur 342 003, India

B. D. Goswami

Guwahati Medical College, Guwahati 781 032, India

S. K. Issar

Bhilai Steel Plant Hospital, Bhilai 490 009, India

\author{
A. K. Jain \\ Choithram Hospital and Research Centre, Indore 452 014, India \\ G. Loganathan \\ GL Hospital, Salem 636 004, India \\ S. P. Misra \\ Moti Lal Nehru Medical College, Allahabad 211 001, India \\ C. Ganesh Pai \\ Kasturba Medical College, Manipal 576 104, India
}

M. Philip

P V S Memorial Hospital, Kochi 682 017, India

A. S. Puri

G B Pant Hospital, Delhi 110 002, India

G. Ray

B R Singh Hospital Eastern Railway, Kolkata 700 014, India

S. P. Singh

S C B Medical College, Cuttack 753 007, India

\author{
A. Sood \\ Dayanand Medical College and Hospital, Ludhiana 141 001, India \\ V. Subramanian \\ St. James Hospital, Leeds, United Kingdom
}


Abstract In 2012, the Indian Society of Gastroenterology's Task Force on Inflammatory Bowel Diseases undertook an exercise to produce consensus statements on Crohn's disease (CD). This consensus, produced through a modified Delphi process, reflects our current recommendations for the diagnosis and management of $\mathrm{CD}$ in India. The consensus statements are intended to serve as a reference point for teaching, clinical practice, and research in India.

Keywords Aminosalicylates · Biologics $\cdot$ Complications · Diagnosis $\cdot$ Fistula $\cdot$ Inflammatory bowel disease .

Management

\section{Introduction}

The Task Force on Inflammatory Bowel Diseases (IBD) of the Indian Society of Gastroenterology in 2012 brought out a set of consensus statements on ulcerative colitis in India [1]. In 2012, using a similar process of consensus, the Task Force also identified a set of consensus statements for the diagnosis and management of Crohn's disease (CD) in India. These statements reflect the most current recommendations and guidelines with respect to $\mathrm{CD}$ in India.

\section{Methods}

The methods employed for this set of consensus statements were similar to those employed for the earlier consensus on ulcerative colitis (UC) [1] and are briefly detailed here. A modified Delphi process [2] was adopted to develop the consensus statements. Four areas were defined, namely epidemiology, diagnosis, medical management, and surgical management. In each of the sections, the issues were determined according to perceived clinical importance. BSR, GKM, and VA generated a list of statements, which were then taken up for discussion, revision, voting, and final consensus. The initial statements were circulated to the Task Force members. The first vote was conducted by email, without explanation or justification for the statements; feedback regarding the statements was collated and modifications made where appropriate. Literature on $\mathrm{CD}$, including both Indian and international studies, was collated and copies were circulated to all the members by post. An attempt was made to include all Indian studies both full papers and those published as abstracts. The international literature that was circulated included all the recent societal guidelines on $\mathrm{CD}$ as well as original articles on $\mathrm{CD}$. The members were advised that they could change their vote on the statements after reviewing the literature. The results of the second vote were collated. Finally, the group met and discussed the statements developed based on feedback from the two rounds of votes by email. The third face-toface meeting was held in Vellore and included two external observers-Professor Henry Binder from Yale University, New Haven, CT, USA and Professor Ian Roberts-Thomson, University of Adelaide, Adelaide, SA, Australia. There were also invited members representing experts in histopathology and surgery. The group discussed the evidence to support specific statements; the evidence was presented in five parts by VJ, GKM, UCG, BSR, BP, and VA. All relevant literature available for each statement was reviewed with emphasis on Indian data when available. The third vote followed these presentations, and was captured using electronic vote pads to maintain anonymity. The options given for each statement were (a) accept completely, (b) accept with some reservation, (c) accept with major reservation, (d) reject with reservation, and (e) reject completely. Consensus on a statement was considered achieved when $80 \%$ or more of the voting members chose to "accept completely" or "accept with some reservation" the statement. A statement was considered refuted when $80 \%$ or more of the voting members indicated "reject completely" or "reject with some reservation." When no consensus was reached on a particular statement, it was modified and a second vote was sought. If the second vote remained inconclusive, the statement was either deleted or modified according to the discussion. The participants were then asked to grade the level of evidence available and the strength of recommendation for the accepted statements, using a modification of the scheme suggested by the Canadian Task Force on the Periodic Health Examination (Table 1) [3].

Table 1 Quality and grade of evidence

\begin{tabular}{|c|c|c|c|}
\hline \multicolumn{2}{|c|}{ Quality of evidence } & \multicolumn{2}{|c|}{ Strength of recommendation } \\
\hline Grade & Description & Grade & Description \\
\hline I & $\begin{array}{l}\text { Evidence obtained from } \\
\text { at least one RCT }\end{array}$ & A & $\begin{array}{l}\text { There is good evidence } \\
\text { to support the } \\
\text { statement }\end{array}$ \\
\hline II-1 & $\begin{array}{l}\text { Evidence from well controlled } \\
\text { trials without randomization }\end{array}$ & $\mathrm{B}$ & $\begin{array}{l}\text { There is fair evidence } \\
\text { to support the } \\
\text { statement }\end{array}$ \\
\hline II-2 & $\begin{array}{l}\text { Evidence from well designed } \\
\text { cohort or case control study }\end{array}$ & $\mathrm{C}$ & $\begin{array}{l}\text { There is poor evidence } \\
\text { to support the } \\
\text { statement }\end{array}$ \\
\hline II-3 & $\begin{array}{l}\text { Evidence from comparison } \\
\text { between time or place with } \\
\text { or without intervention }\end{array}$ & $\mathrm{D}$ & $\begin{array}{l}\text { There is fair evidence } \\
\text { to refute the } \\
\text { statement }\end{array}$ \\
\hline III & $\begin{array}{l}\text { Opinion of experienced } \\
\text { authorities and expert } \\
\text { committees }\end{array}$ & $\mathrm{E}$ & $\begin{array}{l}\text { There is good evidence } \\
\text { to refute the } \\
\text { statement }\end{array}$ \\
\hline
\end{tabular}

$R C T$ randomized controlled trials 


\section{Consensus statements on Crohn's disease of the Indian Society of Gastroenterology-Inflammatory Bowel Disease Task Force}

\section{Epidemiology and clinical manifestations}

1. $\mathrm{CD}$ is increasingly being diagnosed in India

Voting: Unanimous

Level of evidence: III

Grade of recommendation: C

The first published report of CD in India was in 1970 [4]. In the same decade, there were several reports of $\mathrm{CD}$ being diagnosed in Indian immigrants to other countries [5-7]. A PubMed search reveals that the number of publications dealing with CD increased from 2 in the 1970s to more than 40 in the years from 2010 to 2014 . This corroborates the opinion of all gastroenterologists on the panel that $\mathrm{CD}$ is increasingly being diagnosed in India. Although it is often stated that the incidence of $\mathrm{CD}$ is increasing in India, there is no community-based incidence or prevalence data on CD in India, and it is not possible to say whether the apparent rise in frequency of diagnosis is due to an increasing incidence of the disease in India, or due to increasing recognition of the disease by physicians.

2. The prevalence of CD in Indian immigrants to developed countries approaches that of the local population of those countries

Voting percentage: A27, B55, C18

Level of evidence: II-2

Grade of recommendation: B

The prevalence of CD is assumed to be low in India. However, Indians do appear to have the genetic predisposition to develop CD if they migrate to other countries. Studies of migrants from South Asia to developed countries have proved particularly informative in this regard. In Leicestershire, UK, the standardized prevalence of CD in Europeans was $75.8 / 10^{5}$ while among South Asians, it was $33.2 / 10^{5}$ [8]. In the same area, the standardized incidence in South Asians during the 1980s was 2.4/10 $/$ year in Hindus, 3.4/10 $/$ year in Sikhs, and 5.4/10 $/$ year in Muslims, none of these being significantly different from that in Europeans, which was 4.7/10 $5 /$ year [9]. In the borough of Tower Hamlets in London, UK, the mean standardized incidence of $\mathrm{CD}$ in Bangladeshis was 1.2/10 $/$ year in the 1970 s and $2.3 / 10^{5} /$ year in the 1980 s compared with $3.8 /$ $10^{5} /$ year and 4.1/10 $/$ year in Europeans [10]. Analysis of data from the 1970 British Cohort Study, a longitudinal birth cohort study of all those born 5-11 April 1970 in Great Britain, showed that young Asians born in Britain were significantly more likely than indigenous Europeans to have a diagnosis of IBD by the age of 26 years [11]. A study in British Columbia showed that during the period 1996-2001, incidence of CD in South Asians was 6.41/10 compared to $3.45 / 10^{5}$ for the non-South Asian population [12]. In an older study in Derby, UK, the mean incidence of CD in people from the Indian subcontinent was $4.39 / 10^{5}$ per year ( $95 \%$ confidence intervals $1.61-10.88 / 10^{5}$ per year) for 1980-1985 and was not significantly different compared to the mean incidence of $7.47 / 10^{5}$ per year $(95 \%$ confidence intervals $6.03-9.25 / 10^{5}$ per year) for the general population [13].

3. Extraintestinal manifestations are not uncommon in Indian patients with $\mathrm{CD}$

Voting: A45, B50, C5

Level of evidence: II-2

Grade of recommendation: B

About one third of patients with CD are expected to develop extraintestinal inflammatory manifestations [14]. Anecdotal descriptions of extraintestinal manifestations of CD were reported from India earlier [15]. Later studies from India indicated that 62 of $200 \mathrm{CD}$ patients $(31 \%)$ in one series and 61 of 223 patients $(27.4 \%)$ in another had extraintestinal manifestations $[16,17]$. The Indian Society of Gastroenterology-Inflammatory Bowel Disease (ISGIBD) Task Force in its survey of 409 patients with CD found that more than half of the patients $(59 \%)$ had extraintestinal symptoms [18]. In many Indian studies, "arthralgia" has been counted as "arthritis" without documentation and this very likely has increased the prevalence of extraintestinal manifestations dramatically. Nevertheless, as more subtle symptoms are identified as being associated with changes and with the increasing use of imaging, it is possible that quite a significant number of $\mathrm{CD}$ patients are found to have some evidence or other of arthropathy.

4. The peak age of Indian patients with CD is $30-40$ years

Voting: A91, B9

Level of evidence: II-2

Grade of recommendation: B

Data on 409 patients with CD collected by the ISG-IBD Task Force revealed a mean (SD) age of 35.8 (13.8) years [18]. In another recent series of 352 patients, the mean (SD) age was 35 (13) years [19]. In a multicentre series of 182 patients, mean (SD) age was 34.5 (13.6) years [20]. Similar mean ages have been reported from other parts of India in limited numbers of patients [21,22].

5. A history of IBD affecting a first-degree relative of a CD patient is not uncommon

Voting: A45, B55

Level of evidence: II-3

Grade of recommendation: B 
The data collected by the ISG-IBD Task Force on 409 patients with $\mathrm{CD}$ showed that $4.6 \%$ of them reported a definite diagnosis of IBD in at least one other member of their family [18].

6. The most common three mutations in nucleotide-binding oligomerization domain 2 (NOD2) gene described in Caucasians have not been found in Indian patients with $\mathrm{CD}$

Voting: A86, B14

Level of evidence: I

Grade of recommendation: A

Mutations in the NOD2 (CARD15) gene were the first genetic abnormalities to be reported in patients with $\mathrm{CD}$. In Western patients, three mutations are very common - two missense mutations namely Arg702Trp (SNP8, C/T) and Gly908Arg (SNP12, G/C) and a frameshift mutation namely Leu1007fsinsC (SNP13, -/C) - in the NOD2 gene [23]. The above NOD2 gene mutations, particularly when two occur simultaneously in an individual, have been associated with severe and complicated CD [24]. Juyal et al. studied 298 UC, 25 $\mathrm{CD}$, and 262 controls in northern India and did not find any of these 3 common mutations [25]. Pugazhendhi et al. studied 82 patients with CD and 149 controls and did not find evidence of these 3 mutations in any of the participants [26]. Mahurkar et al. in $411 \mathrm{UC}$ patients, $241 \mathrm{CD}$ patients, and 442 healthy individuals did not find a single individual with any of these 3 mutations [27]. Given these large numbers, it seems quite safe to conclude that these 3 mutations do not occur in Indians and specifically not in Indian patients with CD.

7. The diagnosis of $\mathrm{CD}$ should be based on a combination of clinical, endoscopic, histological, and radiological features and with satisfactory exclusion of tuberculosis and other infective causes

Voting: A91, B9

Level of evidence: II-2

Grade of recommendation: B

The diagnosis of $\mathrm{CD}$ cannot be established by a single test. It requires to be based on a combination of clinical presentation, endoscopy, imaging, histology, and if possible examination of an operative specimen [28]. Microscopic features are much better assessed on surgical pathology of resected specimens, but there may be a number of clues to the diagnosis on mucosal biopsies obtained during endoscopy [29, 30]. In the Western setting, the difficulty usually lies in distinguishing between Crohn's colitis and ulcerative colitis, and $5 \%$ to $10 \%$ of patients may shift between categories in the first few years after diagnosis [31]. The diagnosis of indeterminate colitis is often arbitrarily made. In India, the diagnosis is advisably made on a constellation of features, including the clinical presentation; characteristic endoscopic features including deep ulcers, longitudinal ulcers, cobblestoning, and skip lesions; appropriate
Table 2 Symptoms in Crohn's disease patients in India

\begin{tabular}{|c|c|c|c|c|}
\hline Features & $\begin{array}{l}\text { Amarapurkar } \\
\text { et al. } 2008 \\
\text { [22] }\end{array}$ & $\begin{array}{l}\text { Makharia } \\
\text { et al. } 2010 \\
\text { [33] }\end{array}$ & $\begin{array}{l}\text { Pugazhendhi } \\
\text { et al. } 2011 \\
\text { [16] }\end{array}$ & $\begin{array}{l}\text { ISG-IBD } \\
\text { Task } \\
\text { Force } 2012 \\
{[18]}\end{array}$ \\
\hline$N$ & 26 & 53 & 200 & 409 \\
\hline $\begin{array}{l}\text { Median } \\
\text { duration } \\
\text { (months) }\end{array}$ & 58.1 & 53.3 & & 48 \\
\hline $\begin{array}{l}\text { Chronic } \\
\text { diarrhea }\end{array}$ & 69.3 & 84.9 & 67.5 & 64.6 \\
\hline Hematochezia & 30.7 & 67.9 & 46.0 & 42.2 \\
\hline Fever & 23.2 & 28.3 & 49.0 & \\
\hline Weight loss & 69.2 & 54.7 & 74.5 & 66.1 \\
\hline $\begin{array}{l}\text { Abdominal } \\
\text { pain }\end{array}$ & 65.6 & 69.8 & 76.5 & 74.9 \\
\hline Ascites & 7.7 & & & \\
\hline $\begin{array}{l}\text { Perianal } \\
\text { disease }\end{array}$ & & 30.1 & & 11.8 \\
\hline
\end{tabular}

$I S G-I B D$ Indian Society of Gastroenterology-Inflammatory Bowel Disease

radiological findings including skip lesions, transmural inflammation, mesenteric fibro-fatty proliferation, and longitudinal ulcerations; and histology indicating transmural inflammation and/or granulomas [32]. The typical clinical and endoscopic features of patients with CD in India are shown in Tables 2 and $3[16,22,33,34]$. Particularly in India and other developing countries, the difficulty lies in distinguishing CD from infective conditions including tuberculosis.

8. The diagnosis of CD may be considered definite when there is demonstration of ulceration in the small bowel and/or colon with either non-caseating granulomas or transmural inflammation demonstrated on histology, and satisfactory exclusion of tuberculosis in appropriate clinical context

Voting: A59, B27, C14

Level of evidence: II-2

Grade of recommendation: A

Table 3 Colonoscopic features in Crohn's disease in India

\begin{tabular}{llll}
\hline & $\begin{array}{c}\text { Amarapurkar et al. } \\
2008[22]\end{array}$ & $\begin{array}{c}\text { Makharia et al. } \\
2010[33]\end{array}$ & $\begin{array}{c}\text { Dutta et al. } \\
2011[34]\end{array}$ \\
\hline$N$ & 26 & 53 & 30 \\
Skip lesions & 23.1 & 66 & 36.7 \\
Aphthoid ulcers & 34.6 & 54.7 & 36.7 \\
Linear ulcers & 57.7 & 30.1 & 40.0 \\
Nodularity & & 24.5 & 30.0 \\
Cobblestoning & 57.7 & 16.9 & 10.0 \\
Stricture & 30.7 & & \\
\hline
\end{tabular}


$\mathrm{CD}$ is identified pathologically as transmural bowel inflammation, with or without granulomas, of unknown etiology. Inflammation confined to the mucosa may occur in the colon in a number of infectious colitides and in ulcerative colitis. In the small intestine, mucosal inflammation may occur in a number of infective or allergic conditions. Transmural inflammation of the intestine or colon is rare in any of the above diseases and occurs mainly in CD. Granulomas are collections of epithelioid histiocytes, the outlines of which are often vaguely defined. Necrosis is usually not apparent in the granulomas of CD. Only granulomas in the lamina propria not associated with active crypt injury may be considered as a feature of $\mathrm{CD}$. Non-caseating granulomas and small collections of epithelioid histiocytes and giant cells may be detected in infectious colitis. Granulomas occur in mycobacterial, chlamydial, and Yersinia infection while microgranulomas may occur in salmonellosis and Campylobacter infection. Therefore, it is important that the diagnosis be set only in an appropriate clinical context, such as any of the major clinical presentations known to be associated with CD. In India, the major differential diagnostic condition that has clinical, endoscopic, imaging, and histological similarities to $\mathrm{CD}$ is intestinal tuberculosis. The distinction can be made relatively clearly in resected specimens of bowel. However, there have been attempts to differentiate the two diseases using mucosal biopsies obtained during colonoscopy (Table 4). However, satisfactory exclusion of intestinal tuberculosis as the alternative diagnosis also involves culture and staining for acid-fast bacilli of mucosal biopsies for tuberculosis, and a search for extraintestinal tuberculosis [16, 33-35].

Table 4 Histological differences between mucosal biopsies in Crohn's disease and tuberculosis

\begin{tabular}{|c|c|c|c|c|c|c|}
\hline & \multicolumn{2}{|c|}{$\begin{array}{l}\text { Pulimood et } \\
\text { al. } 1999 \\
{[29]}\end{array}$} & \multicolumn{2}{|c|}{$\begin{array}{l}\text { Pulimood et } \\
\text { al. 2005 } \\
{[30]}\end{array}$} & \multicolumn{2}{|c|}{$\begin{array}{l}\text { Makharia et } \\
\text { al. } 2010 \\
\text { [33] }\end{array}$} \\
\hline & $\begin{array}{l}\text { TB } \\
(20)\end{array}$ & $\begin{array}{l}\text { CD } \\
(20)\end{array}$ & $\begin{array}{l}\text { TB } \\
(33)\end{array}$ & $\begin{array}{l}\mathrm{CD} \\
(31)\end{array}$ & $\begin{array}{l}\text { TB } \\
(53)\end{array}$ & $\begin{array}{l}\text { CD } \\
(53)\end{array}$ \\
\hline Caseous necrosis & 40 & 0 & 36 & 0 & 13.2 & 1.8 \\
\hline Confluent granulomas & 60 & 0 & 42 & 3 & & \\
\hline 5 granulomas/biopsy site & 40 & 0 & 45 & 0 & 22.2 & 3.7 \\
\hline Large granulomas & 90 & 5 & 51 & 0 & 27 & 9.4 \\
\hline Submucosal granulomas & 45 & 5 & 39 & 6 & 20.7 & 7.5 \\
\hline $\begin{array}{l}\text { Ulcers lined by epithelioid } \\
\text { granulomas }\end{array}$ & 45 & 5 & 61 & 0 & 22.6 & 7.5 \\
\hline $\begin{array}{l}\text { Disproportionate } \\
\text { submucosal inflammation }\end{array}$ & 65 & 5 & - & - & 33.9 & 16.9 \\
\hline $\begin{array}{l}\text { Distant architectural } \\
\text { abnormalities }\end{array}$ & - & - & 0 & 62 & - & - \\
\hline
\end{tabular}

Values shown are percentage of cases with the feature in each group $T B$ tuberculosis, $C D$ Crohn's disease
9. The absence of the above histological features does not exclude a diagnosis of $\mathrm{CD}$ in the appropriate clinical setting

Voting: A59, B23, C5, D9, E4

Level of evidence: III

Grade of recommendation: $\mathrm{C}$

Granulomas are found in mucosal biopsies in less than a half of patients with $\mathrm{CD}$. It is not possible to diagnose transmural inflammation in mucosal biopsies. Under these conditions, the diagnosis of $\mathrm{CD}$ continues to be made in the appropriate clinical context where imaging shows skip lesions, deep ulceration, and typical linear or stellate ulcers, along with mucosal biopsy findings of inflammation. Under the circumstances, the diagnosis must always be reviewed and reconsidered at every stage, especially in the event that the patient does not respond to therapy for $\mathrm{CD}$.

10. Whenever a clear distinction is not made between $C D$ and tuberculosis, a trial of anti-tuberculosis therapy should be considered

Voting: A73, B23, C5

Level of evidence: III

Grade of recommendation: $\mathrm{C}$

The difficulties in distinguishing between $\mathrm{CD}$ and intestinal tuberculosis have been alluded to earlier. There are often situations where the diagnosis remains unclear despite extensive investigation. Under these circumstances, the experts considered that it was appropriate to consider giving a trial of antituberculosis treatment. This is based on the rationale that the treatment of tuberculosis is finite, whereas treatment for $\mathrm{CD}$ continues indefinitely. Also, there is a risk in treating patients with corticosteroids if there is a possibility that the diagnosis may actually be tuberculosis. Obviously, the decision to treat for one disease or the other would take into account other clinical considerations including the nature of presentation of the patient, whether acutely ill and requiring immediate definitive therapy or not. It would also be accompanied by a complete discussion with the patient of the possibilities and therapeutic alternatives.

11. Patients treated empirically for intestinal tuberculosis should be re-evaluated at the end of the anti-tuberculosis treatment, if $\mathrm{CD}$ is a differential diagnostic possibility

Voting: A82, B18

Level of evidence: II-2

Grade of recommendation: B

In patients treated for intestinal tuberculosis, it is expected that there will be complete resolution of the lesions, detectable by endoscopy or by imaging, following therapy. In a study of 49 patients with ileocecal or colonic tuberculosis treated with antituberculous treatment, complete healing of mucosal lesions was observed in $73.5 \%$ of the participants at the end of 2 months and in $100 \%$ of participants at the end of 6 months [36]. It is therefore 
appropriate to re-endoscope patients who were treated empirically for intestinal tuberculosis and to establish complete mucosal healing at the end of 6 months. The Task Force was in agreement that this should be done, in view of the possibility that recurrent symptoms would make it difficult to judge whether the patient was in fact having intestinal tuberculosis or $\mathrm{CD}$ during the first episode.

12. Simultaneous treatment with anti-tuberculosis drugs and anti-inflammatory drugs for $\mathrm{CD}$ should be discouraged

Voting: A82, B13, C5

Level of evidence: III

Grade of recommendation: $\mathrm{C}$

In India, the practice of treating simultaneously with antituberculosis medication and with anti-inflammatory drugs for $\mathrm{CD}$ is seen commonly among physicians. The Task Force was of the opinion that this practice should be strongly discouraged. Some experts felt that exceptions may be made in emergency situations but, as such situations could not be defined clearly, this clause was dropped during discussion.

13. Initial symptomatic improvement may occur with antituberculosis drugs in a proportion of patients with $\mathrm{CD}$

Voting: A68, B27, C0, D0, E5

Level of evidence: II-2

Grade of recommendation: B

All Indian series of $C D$ patients report that a third or more of patients had received anti-tuberculosis treatment prior to establishment of a diagnosis of $\mathrm{CD}[18,33,35]$. A significant number of these patients responded symptomatically in the initial phases of anti-tuberculosis treatment. The proportion of patients in whom such improvement occurred, and the duration of such a response, has not, however, been well documented.

14. Complete mucosal healing should be considered as evidence for tuberculosis in patients treated empirically with antituberculosis drugs

Voting: A67, B33

Level of evidence: I

Grade of recommendation: A

As cited earlier, all of 49 patients with ileocecal or colonic tuberculosis treated with anti-tuberculosis treatment showed complete mucosal healing by lower upper gastrointestinal (GI) endoscopy at the end of 6 months [36]. In a recent, as yet unpublished study, done collaboratively across three centers in India, 143 of 144 patients treated for abdominal tuberculosis with complete response did not have recurrence of tuberculosis at the end of 1 year [37]. Complete mucosal healing occurs in CD treated with appropriate therapy including immune suppressants and biologics, but not in patients with therapy directed at other etiologies including tuberculosis.
15. The role of Mantoux testing or interferon gamma release assays in differentiating CD from tuberculosis is not established

Voting: A64, B27, C5, D5

Level of evidence: III

Grade of recommendation: $\mathrm{C}$

Mantoux testing using purified protein derivative has long been used to establish a diagnosis of latent tuberculosis. The interferon gamma release assays (IGRA) have been used for the same purpose [38]. While a positive Mantoux or IGRA test may establish the presence of latent tuberculosis, it does not necessarily mean that the individual's intestinal disease is tuberculosis. It is well known that biologics may activate latent tuberculosis in patients with CD treated with biologics. Such individuals are indeed identified by the presence of a positive Mantoux or IGRA test. In a recent study, Lee et al. followed up 60 individuals in whom the diagnosis of $\mathrm{CD}$ or intestinal tuberculosis remained indeterminate [39]. Of 20 individuals who tested positive with IGRA and followed up over time, $12(60 \%)$ eventually were diagnosed to have intestinal tuberculosis, 6 were diagnosed to have $\mathrm{CD}$, and 2 had Behcet's syndrome. Of 40 with a negative IGRA, 38 (95\%) had a final diagnosis of CD, 1 was diagnosed to have Behcet's, and 1 was diagnosed to have nonspecific colitis. In this very selected group of patients, IGRA had a negative predictive value of $95 \%$ for a diagnosis of $\mathrm{CD}$ and had a likelihood ratio of 6.6 for CD. In another study from Korea, 7 of 72 patients with $C D$ and 50 of 75 patients with intestinal tuberculosis had positive Quantiferon TB Gold tests [40]. Based on this study, IGRA had a negative predictive value for CD of $72 \%$, and negative IGRA was associated with a likelihood ratio of 2.7 for $\mathrm{CD}$.

16. Testing for antibody to Saccharomyces cerevisiae antigens (ASCA) does not help to differentiate CD from intestinal tuberculosis

Voting: A77, B23

Level of evidence: II-2

Grade of recommendation: A

ASCA is often used to distinguish CD from ulcerative colitis, being positive in the former [41]. In India, the diagnostic difficulty usually lies in distinguishing intestinal tuberculosis from CD. ASCA clearly does not help in this context. Ghoshal et al. found that 8 of 16 patients with intestinal tuberculosis and 10 of 16 patients with CD had ASCA antibodies [42]. In a study from New Delhi including 59 patients with $\mathrm{CD}$ and 30 patients with intestinal tuberculosis, ASCA was positive in $61 \%$ of CD patients compared to $66 \%$ of intestinal tuberculosis patients [43]. Another study found ASCA positivity in 9 of $30 \mathrm{CD}$ patients compared to 3 of 30 patients with intestinal tuberculosis, a difference that was not statistically significant [34]. 
17. TB-PCR of biopsies does not reliably discriminate intestinal tuberculosis from $\mathrm{CD}$

Voting: A67, B29, C0, D4

Level of evidence: II-2

Grade of recommendation: B

Tuberculosis of the intestine is a paucibacillary disease. AFB culture of mucosal biopsies typically yield a diagnosis of tuberculosis in a third or less of patients [32]. Earlier studies have shown that in tuberculosis, PCR for $M y$ cobacterium tuberculosis may be positive in $22 \%$ to $64 \%$ of mucosal biopsies [44-46], while being positive in $0 \%$ to $5 \%$ of patients with $\mathrm{CD}$. In one study, in situ PCR for tuberculosis in mucosal biopsies was positive in 6 of 20 intestinal tuberculosis patients compared to 1 of $20 \mathrm{CD}$ patients [47]. PCR of stool for M. tuberculosis DNA was helpful in one study to differentiate between $\mathrm{CD}$ and intestinal tuberculosis, but this has not been substantiated by other groups [32].

18. Presence of caseating granuloma, acid-fast bacilli or a positive M. tuberculosis culture are diagnostic for tuberculosis

Voting: A100

Level of evidence: II-1

Grade of recommendation: A

$\mathrm{CD}$ is characterized by non-caseating granulomas. When the differential diagnosis rests between $\mathrm{CD}$ and intestinal tuberculosis, the presence of acid-fast bacilli on biopsies or a positive culture for M. tuberculosis is diagnostic of tuberculosis. Caseation necrosis in granulomas is also diagnostic of tuberculosis in this setting. In two series from southern India, caseation necrosis was found in mucosal biopsies from 20 to 53 patients with intestinal tuberculosis compared to 0 of 51 patients with $\mathrm{CD}[29,30]$. In a series from northern India, caseation necrosis in mucosal biopsies was found in 7 of 53 patients with intestinal tuberculosis compared to 1 of 53 patients with $\mathrm{CD}$ [33].

19. Patients with $C D$ should undergo evaluation for the extent of the disease

Voting: A95, B5

Level of evidence: III

Grade of recommendation: C

CD may affect both small and large intestine. The clinical manifestations depend on the location and extent of the disease, and treatment often takes these into consideration. The Montreal classification of CD depends on a complete assessment of extent of disease [48].

20. Segmental ileocolonic biopsies should be obtained for the diagnosis and evaluation for the extent of the disease

Voting: A77, B23
Level of evidence: II-1

Grade of recommendation: A

Many studies have shown that multiple biopsies from different segments of the colon and from the terminal ileum are useful in establishing both diagnosis and extent of $\mathrm{CD}$. The importance of multiple biopsies at these levels as the first line investigation for $\mathrm{CD}$ has been emphasized in the European Crohn's and Colitis Organization (ECCO) guidelines [49]. A study in southern India showed that the diagnostic features of $\mathrm{CD}$ increased progressively when biopsies were taken from larger numbers of sites, from $40 \%$ with mucosal biopsies from one region of the colon, to near $100 \%$ when eight different sites were biopsied in the colon and ileum [30]. Upper GI endoscopy and biopsy are also important in providing additional evidence for a diagnosis of CD. Biopsies at upper GI endoscopy should be taken from areas with ulceration, but also from apparently normal mucosa in the second part of the duodenum and from the incisura of the stomach. Upper GI involvement was found in $16 \%$ of 119 patients with CD studied prospectively [50]. Focal cryptitis of the duodenum and focally enhanced gastritis may aid the diagnosis of $\mathrm{CD}$, particularly in children with IBD in whom the diagnosis is sometimes made only on the basis of upper GI biopsy [51]. Evaluation of extent helps in targeting therapy as regionspecific delivery of mesalamine and steroids becomes available. It also helps prior to making a decision to proceed to surgery in selected patients. Factors that can be cited against protocol evaluation of extent in all patients include issues of cost, lack of available of facilities, and the question of whether finding asymptomatic involvement of a region changes management.

21. The presence of large and confluent granulomas in mucosal biopsies favors $\mathrm{TB}$, but does not completely exclude $\mathrm{CD}$

Voting: A68, B32

Level of evidence: II-1

Grade of recommendation: A

In three Indian studies, mucosal biopsy findings of large granulomas, greater than $400 \mu$ in diameter, was noted in $0 \%$ to $9.4 \%$ of patients with CD compared to $27 \%$ to $90 \%$ of patients with intestinal tuberculosis $[29,30,33]$. In these studies, confluent granulomas were recorded in $0 \%$ to $3 \%$ of CD biopsies compared to $42 \%$ to $60 \%$ in tuberculosis. In a study from Korea, large granulomas and confluent granulomas were respectively found in $19.2 \%$ and $7.8 \%$ of $\mathrm{CD}$ biopsies compared to $75 \%$ and $46.2 \%$ of biopsies from intestinal tuberculosis [52]. Thus, the presence of these findings favors intestinal tuberculosis but does not completely exclude CD.

22. Small bowel involvement may be assessed using either radiological tests (computed tomography-/magnetic 
resonance-enterography/enteroclysis, barium studies) or endoscopic tests (capsule and/or balloon assisted enteroscopy)

Voting: A91, B9

Level of evidence: II-1

Grade of recommendation: A

Disease extent in CD is typically assessed using upper and lower GI endoscopy which is followed by evaluation of the small bowel. Traditionally, barium meal and enteroclysis studies were used to identify small bowel involvement and diagnostic features of $\mathrm{CD}$ were described on such imaging. Barium enteroclysis has largely been replaced by CT and MR, both of which can detect and characterize mucosal and extraluminal lesions [49]. A meta-analysis has shown that capsule endoscopy was superior to barium, ileocolonoscopy, MR, and CT in the recognition of non-stricturing small bowel CD [53]. Capsule enteroscopy and balloon enteroscopy perform similarly but the latter is associated with greater risk [54]. Due to the cost of capsule enteroscopy as well as its disadvantages in stricturing CD of the small bowel, CT and MR enterography are the investigations of choice to determine extent and activity. Transabdominal ultrasound is a useful additional tool to evaluate disease activity [49].

23. Presence of minute lesions or isolated aphthous ulcers detected either at ileocolonoscopy or enteroscopy is not sufficient to make a diagnosis of $\mathrm{CD}$

Voting: A82, B18

Level of evidence: II-2

Grade of recommendation: B

Minute lesions and aphthous ulcers may be found in a variety of diseases including $\mathrm{CD}$, tuberculosis, non-steroidal analgesic use, allergic enteropathies, and in a variety of infective conditions such as enteric fever, shigellosis, amebiasis, and helminthiasis [55]. There is no gold standard for the diagnosis of $\mathrm{CD}$, unlike infective conditions where identification of the causative organism can be diagnostic. Studies suggest that small ulcerations and aphthous ulcerations should be present at least for 3 months and be associated with non-caseating granulomas to establish a diagnosis of CD [56].

24. The activity of CD should be assessed using one of the well-defined activity indices

Voting: A82, B18

Level of evidence: I

Grade of recommendation: A

Assessment of disease activity is useful in following progress of the disease over time, in assessing the response to therapy, and in decisions concerning escalation or withdrawal of therapy. A number of indices are available to assess severity of $\mathrm{CD}$ activity including the $\mathrm{CD}$ activity index (CDAI), the Harvey-Bradshaw index, and the CD endoscopic index of severity (CDEIS) [57, 58]. Any of these indices can be used depending on the preference of the caregiver and on the reason for assessing disease severity. All of the indices have been well-validated in numerous trials. The indices are also useful for assessing postoperative recurrence of the disease [59].

25. In patients with prolonged remission wishing to stop therapy, mucosal healing may be documented before stopping therapy

Voting: A42, B38, C5, D5, E10

Level of evidence: III

Grade of recommendation: $\mathrm{C}$

$\mathrm{CD}$ is generally considered to be a lifelong affliction characterized by remission and relapse, which occurs in unpredictable fashion. Complete disappearance of endoscopic and histological lesions has been described as mucosal healing in $\mathrm{CD}$ and occurs with a variety of therapies $[60,61]$. The concept of mucosal healing as a therapeutic end-point gained wide currency when biologics were introduced [62, 63]. Although treatment for CD is considered to be lifelong in the majority of patients, occasional patients may be candidates for cessation of therapy. Under these circumstances, it is probably best to evaluate for mucosal healing prior to cessation of therapy although its presence is not necessarily a guarantee of long-term treatment-free remission [64].

26. The choice of treatment for many patients in India depends substantially on the cost and affordability of the treatment regimens

Voting: A81, B14, C5

Level of evidence: III

Grade of recommendation: $\mathrm{C}$

Treatment of CD in Western setting is often top-down starting with infliximab, especially in fistulizing CD. Western guidelines also advocate the use of biologics in specific situations. The cost of using biologics is not inconsiderable even in Western countries $[65,66]$, and the Task Force felt that it would not be appropriate at the present time to reproduce these guidelines for use in Indian patients with $\mathrm{CD}$. State hospitals in India provide medications free of charge to indigent patients but presently this does not include the use of infliximab for $\mathrm{CD}$. The treatment should thus be individualized based on socioeconomic settings in addition to clinical considerations.

27. Oral mesalamine may induce remission in some patients with mild colonic $\mathrm{CD}$

Voting: A64, B23, C8, D5 
Level of evidence: III

Grade of recommendation: C

Meta-analysis of clinical trials of mesalamine has shown somewhat conflicting results. Low-dose mesalamine ( 1 to $2 \mathrm{~g} /$ day) was not superior to placebo ( $\mathrm{RR}=1.46,95 \%$ CI 0.89 $2.40 ; n=302$ ) and was less effective than corticosteroids. High-dose mesalamine ( 3 to $4.5 \mathrm{~g} /$ day) was not superior to placebo for induction of remission (RR 2.02; $95 \%$ CI 0.75 to $5.45)$ or response $(n=615)$. At the same time, no statistically significant difference was found between high-dose mesalamine and conventional corticosteroids (RR 1.04; $95 \%$ CI 0.79 to $1.36 ; n=178$ ) [67]. Another meta-analysis came up with slightly different conclusions. In 6 randomized controlled trials (RCTs) of mesalamine vs. placebo involving 910 patients, the majority of patients was treated for $6-$ 17 weeks and had ileal or ileocolonic disease [68]. A statistically significant effect of 5-aminosalicylic acid (5-ASA) therapies was noted when remission was used as the outcome. Thirty-two percent achieved remission in the 5-ASA group and $26 \%$ in the placebo group. Despite the paucity of studies in mild $\mathrm{CD}$, gastroenterologists worldwide appear to use mesalamine in CD. Forty-two percent of 285 Australian gastroenterologists who were sent a questionnaire by email responded. Five ( $4 \%$ ) never used 5-ASA drugs in $\mathrm{CD}$. The drugs were most commonly prescribed for patients with colonic $(96 \%)$ or ileocolonic $(92 \%)$ disease location, inflammatory disease behavior $(80 \%)$, and mild disease activity (97\%). The majority (64\%) used a dose of 1-3 g/day, but only $6 \%$ used over $4.5 \mathrm{~g}$ /day [69]. Survey of a group of gastroenterologists in Asia also revealed that the majority preferred to use mesalamine for the control of mild-to-moderate $\mathrm{CD}$ and also to maintain remission in these patients [70]. In a study from Sweden, 165/537 (31\%) CD patients had monotherapy with mesalamine with complete or partial response in $75 \%$, and prolonged response in $36 \%$ [71]. In that study, $23 \%$ of patients were mesalamine-dependent.

28. Oral mesalamine alone does not induce remission in moderate to severely active $\mathrm{CD}$

Voting: A86, B14

Level of evidence: I

Grade of recommendation: A

Meta-analysis of studies of mesalamine in induction of remission in moderate to severe $\mathrm{CD}$ have shown no benefit of either low-dose or high-dose mesalamine over placebo in induction of remission in these patients [67]. A meta-analysis of 22 RCTs indicated little evidence that mesalamine was superior to placebo in inducing remission in CD [68]. These studies were undertaken largely in patients with moderate to severe CD. The American College of Gastroenterology Task Force on IBD also concluded that 5-ASA therapies are not recommended for inducing remission in active $\mathrm{CD}$. However, their strength of this recommendation was weak and they graded the evidence as being of low quality [72].

29. Mild to moderately active CD localized to terminal ileum may be treated using budesonide

Voting: A57, B33, C5, D0, E5

Level of evidence: I

Grade of recommendation: B

Due to rapid metabolism by cytochrome P-450 enzymes in the liver, budesonide has less systemic bioavailability than conventional corticosteroids and therefore budesonide administered in controlled release formulation targeting release of active drug in the terminal ileum has become an attractive option for treating patients with CD located in the terminal ileum or the right colon. It has long been used in the treatment of active ileal CD [73, 74]. This recommendation was also endorsed by the European Crohn's and Colitis Organization (ECCO) [75]. Budesonide has been found superior to placebo for induction of remission in active $\mathrm{CD}$ [76]. A recent systematic review indicated that budesonide was not effective in maintaining remission in $\mathrm{CD}$ [77].

30. CD limited to the left side of the colon may be treated with sulfasalazine/mesalamines

Voting: A45, B45, C5, D0, E5

Level of evidence: I

Grade of recommendation: B

Two recent meta-analyses showed that sulfasalazine was more effective than placebo in inducing remission in patients with mild CD of the colon $[67,68]$. Sulfasalazine releases the active 5-ASA through bacterial metabolism in the colon, particularly in the left colon. Therefore, mild cases of CD involving predominantly the left colon may be treated with sulfasalazine.

31. Irrespective of the location of the disease, severely active $\mathrm{CD}$ requires conventional corticosteroids for the induction of remission

Voting: A85, B15

Level of evidence: I

Grade of recommendation: A

The National Cooperative CD Study and the European CD Cooperative Study showed that corticosteroids were effective in inducing remission in active CD (Table 5) [78, 79]. A population-based study revealed that $44 \%$ of $C D$ patients remained off corticosteroids and remained in the phase of remission, $36 \%$ remained steroid dependent, and $20 \%$ were steroid-resistant after 1 year of use of corticosteroids [80]. Meta-analysis of clinical trials have shown that corticosteroids 
Table 5 Efficacy of corticosteroids in inducing remission in active Crohn's disease - the National Cooperative Crohn's Disease Study and European Cooperative Crohn's Disease Study studies

\begin{tabular}{|c|c|c|c|c|}
\hline Study & $\begin{array}{l}\text { No. of } \\
\text { patients }\end{array}$ & $\begin{array}{l}\text { Dose } \\
\text { schedule }\end{array}$ & $\begin{array}{l}\text { Treatment } \\
\text { response }\end{array}$ & NNT \\
\hline $\begin{array}{l}\text { National Cooperative } \\
\text { Crohn's Disease } \\
\text { Study [78] }\end{array}$ & 162 & $\begin{array}{l}0.5-0.75 \mathrm{mg} / \mathrm{kg} / \\
\text { day tapering } \\
\text { over } 17 \text { weeks }\end{array}$ & $\begin{array}{l}60 \% \text { active } \\
\text { vs. } 30 \% \\
\text { placebo }\end{array}$ & 3 \\
\hline $\begin{array}{l}\text { European } \\
\text { Cooperative } \\
\text { Crohn's Disease } \\
\text { Study [79] }\end{array}$ & 105 & $\begin{array}{l}1 \mathrm{mg} / \mathrm{kg} / \mathrm{day} \\
\text { tapering over } \\
18 \text { weeks }\end{array}$ & $\begin{array}{c}83 \% \text { active } \\
\text { vs. } 30 \% \\
\text { placebo }\end{array}$ & 2 \\
\hline
\end{tabular}

NNT number needed to treat

were more effective in inducing remission in active $\mathrm{CD}$ than placebo (RR 1.99; $95 \%$ CI 1.51 to $2.64 ; p<0.00001$ ) or 5 ASA (RR 1.65; $95 \%$ CI 1.33 to $2.03 ; p<0.00001$ ) [81]. However, they are associated with adverse events in a higher proportion of patients than either placebo (RR 4.89; $95 \%$ CI 1.98 to 12.07 ; $p=0.0006$ ), or low-dose 5-ASA (RR 2.38; $95 \% \mathrm{CI}$ 1.34 to $4.25 ; p=0.003$ ).

32. Azathioprine and other immunosuppressants may induce remission in patients with $\mathrm{CD}$ but have a gradual onset of action over many weeks

Voting: A74, B26

Level of evidence: I

Grade of recommendation: A

In a large placebo-controlled study, high-dose (25 mg/week) intramuscular methotrexate was significantly better than placebo in inducing remission in $\mathrm{CD}$ patients [RR 0.75, $95 \%$ CI 0.61 to 0.93 ; number needed to treat $(\mathrm{NNT})=5$ ]. Seventeen percent of methotrexate patients withdrew due to adverse events compared to $2 \%$ of patients on placebo (RR 8.00, $95 \%$ CI 1.09 to 58.51) [82]. Studies using oral methotrexate failed to show significant benefit in inducing remission in $C D$ patients [82]. The incidence of adverse events was significantly more common in methotrexate patients $(63 \%)$ than azathioprine patients (26\%) in a small study. In a meta-analysis of placebo-controlled trials, azathioprine and 6-mercaptopurine were shown to have a statistically significant effect on inducing remission, with the effect becoming evident 17-weeks after initiation of therapy [83]. On the other hand, the more recent meta-analysis showed that azathioprine and 6-mercaptopurine were not significantly better than placebo in inducing remission in active CD, although antimetabolites had a steroidsparing effect [84]. The latter meta-analysis included a number of studies in which biologicals were concomitantly given as standard therapy.
33. Nutritional supplementation is an important component of the management of all patients with CD and especially those with extensive small intestinal CD

Voting: A84, B11, C5

Level of evidence: II-2

Grade of recommendation: $\mathrm{B}$

Energy and micronutrient deficiency is common in CD patients, due to dietary restriction, disease activity and loss of protein and blood from ulcerated areas, and surgical resection resulting in shortening of the bowel. These deficiencies are especially common among those with extensive small intestinal disease. In a study from Delhi, $82.8 \%$ of patients with active CD and $38.9 \%$ of patients in remission had features of energy malnutrition [85]. The same group later showed that patients with CD had depletion of both fat mass and fat-free mass during active disease, while depletion of lean mass persisted during quiescent disease [86]. In children, this may result in growth failure [87]. Close attention to nutrition with enteral supplements, parenteral nutrition, and micronutrient supplementation are thus cornerstones of management of these patients [88].

34. All patients with CD presenting with a febrile illness along with worsening disease activity should be evaluated for intraabdominal abscesses using appropriate investigations and should be adequately treated including control of disease activity

Voting: A85, B15

Level of evidence: III

Grade of recommendation: $\mathrm{C}$

Abdominal abscesses are increasingly recognized as presentations of complicated CD. In a recent study, spontaneous abdominal abscesses were noted to occur in $128(5.7 \%)$ of 2,236 patients with CD [89]. The authors noted that antibiotic treatment alone was often sufficient for small abscesses without associated fistulae in immunomodulator-naïve patients. Surgical drainage was associated with the best outcomes in patients with larger abscesses, while some abscesses could be managed with antibiotics and percutaneous drainage. Importantly, following abscess resolution, $60 \%$ of patients could be started on thiopurines and $9 \%$ on biologics, while in $31 \%$, baseline therapy was not modified. While percutaneous drainage is increasingly used, by itself or as a bridge to surgery, as treatment of intraabdominal abscesses in CD [90], in one study, it was found that only one third of abscesses treated with percutaneous drainage showed long-term resolution compared to $90 \%$ of those undergoing immediate surgical drainage [91]. 
35. 5-ASA or sulfasalazine is widely used in patients with $\mathrm{CD}$ in remission; the evidence for this practice is not available

Voting: A66, B29, C5

Level of evidence: III

Grade of recommendation: $\mathrm{C}$

In a meta-analysis of $\mathrm{CD}$ patients in remission, neither sulfasalazine nor mesalamine were effective in preventing relapse in patients with quiescent $\mathrm{CD}$, but in a per protocol analysis, mesalamine appeared to reduce risk of relapse $(\mathrm{RR}=0.79 ; 95 \% \mathrm{CI}=0.66-0.95, \mathrm{NNT}=13)$ [68]. Nevertheless, prescribing patterns reveal that a large number of physicians and gastroenterologists worldwide continue to use aminosalicylates in the treatment of $\mathrm{CD}$ both for induction and maintenance of remission $[69,92,93]$.

36. Azathioprine or 6-mercaptopurine should be used for maintenance of remission of CD limited to terminal ileum, colonic, ileocolonic, or extensive small intestinal CD

Voting: A89, B11

Level of evidence: I

Grade of recommendation: A

$\mathrm{CD}$ is a relapsing and remitting disease. Withdrawal of all therapy results in relapse in a large number of patients. Several studies have attempted to evaluate the role of azathioprine and 6-mercaptopurine (6-MP) in maintaining remission in CD. In two prospective trials enrolling 198 patients, there appeared to be no significant benefit of azathioprine in preventing relapse when compared with placebo $(\mathrm{RR}=0.64 ; 95 \% \mathrm{CI}=0.34$ 1.23) [94]. However, a different approach in which azathioprine was withdrawn in 163 patients in 3 clinical trials, continuance of medication significantly prevented relapse $(\mathrm{RR}=$ $0.39 ; 95 \% \mathrm{CI}=0.21-0.74)$ compared to withdrawal of medication [95]. In meta-analysis of seven trials of azathioprine and one of 6-mercaptopurine, azathioprine prevented relapse in quiescent $\mathrm{CD}$ with an odds ratio of 2.32 (95\% CI 1.55 to 3.49) with a NNT of 6. 6-MP prevented relapse with an odds ratio of 3.32 (95\% CI 1.40 to 7.87$)$ with a NNT of 4 [95]. Withdrawal due to adverse events was more common with azathioprine (OR 3.74; $95 \%$ CI 1.48 to $9.45, \mathrm{NNH}=$ (Number Needed to Harm) $=20$ ) compared to placebo.

37. Corticosteroids, including budesonide, are not recommended in the maintenance of remission in $\mathrm{CD}$

Voting: A84, B16

Level of evidence: I

Grade of recommendation: A

Corticosteroids are effective in inducing remission in CD. Typically, corticosteroids are given in high doses initially but tapered off at the earliest opportunity, and generally not given for longer than 3 months. As earlier mentioned, corticosteroids can be tapered rapidly in many patients, while a small proportion of patients may either not respond to steroids or may become steroid dependent. Long-term corticosteroid use is associated with a number of side effects including weight gain, hirsutism, acne, steroid-induced diabetes, metabolic disease, and susceptibility to infection. It is therefore not desirable to use corticosteroids for the maintenance of remission in patients with $\mathrm{CD}$. In most cases, these patients can be maintained in remission with thiopurines. Budesonide is a poorly absorbed corticosteroid that has been used in the management of $\mathrm{CD}$. A recent meta-analysis has shown that budesonide is not effective for the maintenance of remission in $\mathrm{CD}$, particularly when used beyond 3 months following induction of remission [96]. Although it had minor benefits in terms of lower inflammatory scores and longer time to disease relapse, any benefits were offset by increased numbers of adverse events and more frequent adrenocorticoid suppression in patients receiving budesonide.

38. Most patients with $\mathrm{CD}$ require maintenance treatment for indefinite period

Voting: A79, B16, C0, D0, E5

Level of evidence: I

Grade of recommendation: A

The natural history of $\mathrm{CD}$ is one of remissions and relapses that continue well into advanced life. Evaluation of studies in which maintenance treatment was withdrawn provides some evidence with regard to the need for longterm maintenance treatment of these patients. In 5 studies with 256 patients and 168 controls, continuing azathioprine or 6-MP for long periods of time was associated with fewer relapses. In patients continuing on maintenance treatment with antimetabolites, the odds ratio for relapse, compared to placebo, was 0.22 (95\% CI 0.09-0.53) at 6 months, 0.25 (95\% CI 0.11-0.56) at 12 months, and 0.35 (95\% CI $0.21-$ $0.6)$ at 18 months. Only two trials examined the relapse rate at 5 years, and showed that odds ratio for relapse in the azathioprine arm were lower compared to placebo 0.53 (95\% CI 0.13-2.21) 5 years after stopping therapy [97]. No trials have examined relapse rates beyond 5 years after stopping therapy. Thus, stopping therapy is associated with a risk of relapse of disease, and thus in most patients the treatment needs to be continued indefinitely. The introduction of biologicals led to the expectation that early treatment with these very powerful agents would permanently heal CD. However, the general experience is that such an expectation has not yet been met $[62,98,99]$.

39. There is limited evidence to suggest that oral mesalamine prevents recurrence of $\mathrm{CD}$ in patients who have undergone surgical resection of localized disease

Voting: A74, B26 
Level of evidence: II-2

Grade of recommendation: $\mathrm{C}$

CD is only occasionally permanently cured by surgery. More often, the disease relapses sooner or later after complete resection of the affected segment of the bowel in CD. Metaanalysis of patients with luminal CD in remission after a surgical resection and randomized to 5-aminosalicylates or placebo indicated that mesalamine was more effective than placebo or no therapy $(\mathrm{RR}=0.80 ; 95 \% \mathrm{CI}=0.70-0.92)$ in 834 patients, with an NNT of 10 [68].

40. All patients receiving azathioprine should be monitored for hematological and liver functions at regular intervals

Voting: A100

Level of evidence: II-2

Grade of recommendation: A

Bone marrow suppression, drug-induced hepatitis, and pancreatitis are major adverse effects of azathioprine and 6-mercaptopurine. Pancreatitis usually occurs early in the course of treatment, while marrow suppression and hepatotoxicity may occur at any time. Close long-term follow up of complete blood counts and liver function tests is recommended in all patients taking azathioprine or 6-mercaptopurine. British Society of Gastroenterology guidelines suggest that CBC and LFT should be done weekly for 4 weeks or when the dose is increased, and once the dose is stable to test once in 3 months [100]. Urea and creatinine estimation is recommended at 4, 12, and 26 weeks, and annually thereafter. Measurement of enzyme activity of thiopurine methyltransferase (TPMT) can predict life-threatening myelotoxicity in the one in 300 patients who are TPMT-deficient. However, myelotoxicity can also occur in the presence of normal TPMT activity, and it is therefore recommended that blood count monitoring should remain standard practice [101]. Care is generally needed when using azathioprine along with allopurinol, anticoagulants, and even with aminosalicylates, and smaller doses may be needed or the drug can be avoided [102, 103]. Live vaccines should be avoided in patients taking azathioprine or 6mercaptopurine [102, 103].

41. Infliximab and other anti-tumor necrosis factor antibodies are useful in induction of remission in moderate to severe CD

Voting: A68, B26, C6

Level of evidence: I

Grade of recommendation: A

A number of meta-analyses of clinical trials evaluating anti-tumor necrosis factor (TNF) antibodies in induction of remission at week 4 in $\mathrm{CD}$ have all concluded that these agents are useful in inducing remission in these patients [104-106]. Typically, the likelihood of induction of remission compared to placebo was in the range of relative response rate of 1.66 (95\% CI 1.17-2.36). These agents generally have a good safety profile provided they are used with adequate precaution to exclude concomitant serious infection prior to their usage [107].

42. Infliximab and other anti-tumor necrosis factor antibodies are useful in maintenance of remission in moderate to severe $\mathrm{CD}$ in patients who responded to an induction regimen

Voting: A79, B21

Level of evidence: I

Grade of recommendation: A

The meta-analyses also confirm that, in CD patients who initially responded to biologics, these agents are useful in maintaining remission in these patients up to 56 weeks [104-106]. Typically, the likelihood of maintenance of remission compared to placebo was in the range of relative response rate of 1.78 (95\% CI 1.51-2.09).

43. Infliximab and other anti-tumor necrosis factor antibodies are useful in induction of remission in fistulizing CD

Voting: A44, B39, C17

Level of evidence: I

Grade of recommendation: B

A meta-analysis of seven trials of anti-TNF antibodies in fistulizing CD found only two studies that directly addressed the question of efficacy in fistulizing disease. In short-term treatment, anti-TNF antibodies were significantly better than placebo in healing and closure of fistulae with a relative response rate of 2.44 (95\% CI 1.13-5.28) [105]. Recent studies with longer-term follow up indicate that one third of enterocutaneous fistulae and up to two thirds of perianal fistulae heal with infliximab, with closure being associated with longer-term treatment [108, 109]. Fistula recurrence was noted in a significant number on follow up.

44. Tuberculosis infection must be excluded in patients with CD before starting immunosuppressive therapy

Voting: A67, B28, C0, D5

Level of evidence: II-2

Grade of recommendation: B

Patients with $\mathrm{CD}$ often require lifelong immunosuppressive therapy, which may reactivate latent tuberculosis. The use of immunosuppressant, of biologics, of large doses of corticosteroids, or combinations are considered as indications for treatment of latent tuberculosis $[110,111]$. It is important to exclude tuberculosis in Indian patients with $\mathrm{CD}$ prior to institution of immunosuppressive treatment, since tuberculosis is 
endemic in the country. There is some controversy around the tests to use when screening for latent tuberculosis in immunosuppressed individuals, with studies suggesting both that interferon gamma release assays (IGRA) are less sensitive [112] or more sensitive [113] than tuberculin skin test (TST) in immunosuppressed individuals. It is important to remain aware that tuberculosis may get activated in CD patients on immunosuppressant treatment and to take appropriate steps to monitor them when necessary.

45. Surgical interventions including segmental resection and stricturoplasty may be required in the management of selected patients with $\mathrm{CD}$

Voting: A88, B12

Level of evidence: III

Grade of recommendation: $\mathrm{C}$

In an Italian series, $50 \%$ of patients with $\mathrm{CD}$ were reported to require surgery in the first 5 years after diagnosis, while 74 $\%$ to $96 \%$ had surgery within 10-20 years after diagnosis [114]. The 5-year recurrence rate was $36 \%$ in the patients requiring surgery within 1 year of diagnosis and $14 \%$ in those operated on more than 1 year after diagnosis [114]. The indications for surgery in $\mathrm{CD}$ patients included medical therapy failure (21\%), and complications (79\%) [115]. A little more than half $(53.4 \%)$ of patients had one surgery, the remaining had multiple surgeries. Bowel resection was performed in over two thirds, while a third of patients had stricturoplasty [115]. In two Indian series, approximately a third of patients with CD underwent surgical intervention [17, 20]. Male sex, small bowel disease, perianal disease, and aggressive disease behavior were associated independently with surgical resection [17]. Comparison of South Asians living in London with a northern European CD cohort showed that disease behavior differed significantly between the groups, with less penetrating disease in South Asians compared with that in Northern Europeans and a reduced need for surgery in South Asians [116]. In a small Indian series of 28 operated CD patients, the most common indications for elective surgery was subacute intestinal obstruction (53.5\%), enterocutaneous fistula (10.7\%), and protein-losing enteropathy (7.1\%) [117]. Emergency surgery was performed in $14.2 \%$ patients who presented with perforation and peritonitis, all of whom had resection and exteriorization of the resected ends [117]. There is little randomized data regarding surgery in $\mathrm{CD}$. The decision to operate is based on extent of the disease, location of the disease (e.g. terminal ileal), type of the disease (e.g. fibrostenotic disease), response to therapy, and presence of complications (e.g. perforation, abscess). A multidisciplinary team approach is essential to management.

46. Preservation of bowel length is an important consideration in the surgical treatment of CD patients with multiple levels of involvement

Voting: A88, B12

Level of evidence: II-2

Grade of recommendation: $\mathrm{B}$

Short bowel syndrome was a feared complication of surgery for patients with CD in the past. Short bowel results when major part of small intestine is resected and only $2 \mathrm{~m}$ of small bowel (normal $6 \mathrm{~m}$ ) remains behind. This complication has become less common as surgeons have realized that wide margins are not necessary when resecting diseased bowel in CD [118]. Although segmental resection remains the standard of care for obstruction secondary to strictures in CD, strictureplasty should be considered for patients with a history of prior resections, or in patients with multiple levels of obstruction in the small bowel, who are at increased risk for short bowel syndrome with additional resections [119]. The use of strictureplasty has been shown to be safe with no added risk of malignancy.

47. Endoscopic stricture dilation can be an option for certain patients with obstructive lesions

Voting: A68, B21, C11

Level of evidence: II-2

Grade of recommendation: $\mathrm{B}$

Endoscopic balloon dilatation has been used to treat uncomplicated strictures, with a maximal length of $4 \mathrm{~cm}$, in patients with CD [120]. It has often been combined with local injection of steroids at the site of the stricture. Endoscopic dilation should be done only after control of the disease activity. A systematic review of 13 studies with 347 CD patients showed that endoscopic dilatation was mainly used in postsurgical strictures, with $86 \%$ technical success, $2 \%$ complication rate, and $58 \%$ long-term efficacy [121]. A stricture length equal to or less than $4 \mathrm{~cm}$ was associated with a surgery-free outcome. A large series of 776 dilations in 178 $\mathrm{CD}$ patients was recently reported, $80 \%$ of which were on anastomotic strictures [122]. Technical success rate was $89 \%$. In a subset of patients that were followed up, $80 \%, 57 \%$, and $52 \%$ required no further intervention or one additional dilation only at the end of 1,3 , and 5 years. Cumulative proportions of patients undergoing surgery at 1,3 , and 5 years were $13 \%, 28 \%$, and $36 \%$. Complication rate per procedure was $5.3 \%$, and included bowel perforation ( $1.4 \%$ ), major bleeding requiring blood transfusion $(1.0 \%)$, minor bleeding $(1.3 \%)$, and abdominal pain or fever $(1.5 \%)$.

48. Perianal fistula should be classified as simple or complex using one of the following techniques: examination under anesthesia, magnetic resonance imaging, or endorectal ultrasound

Voting: A84, B16 
Level of evidence: II-2

Grade of recommendation: B

Perianal fistulae are reported to be present in $14.6 \%$ of patients with $\mathrm{CD}$ in a large multicenter study from India [18]. Fistulae are classified as simple when there is only one opening without an associated abscess and as complex if there are multiple openings, there is a horseshoe fistula, or if there are abscesses or adjacent structures are involved. Crohn's fistulae can be considered complex, even if their anatomy is "simple," because of the etiology. MRI and endorectal ultrasound are used to characterize perianal fistulas along with rectal examination under anesthesia. A combination of these modalities leads to optimal results in classification and management of these fistulae [123].

49. In CD patients with perianal fistula, disease activity elsewhere in the gastrointestinal tract should be assessed

Voting: A68, B22, C5, D5

Level of evidence: II-2

Grade of recommendation: B

Activity of perianal fistulae is difficult to assess. MRI often shows persistent fistula tracks in patients who appear to have closed fistula openings externally. Remission is defined as absence of fistula drainage despite gentle finger compression, with closure of all fistulae that were draining at baseline for at least 2 consecutive visits 4 weeks apart. Disease activity elsewhere in the GI tract provides some evidence as to overall disease activity and may guide treatment [124, 125].

50. Adequate surgical drainage is necessary in patients presenting with perianal abscess

Voting: A89, B11

Level of evidence: II-2

Grade of recommendation: B

Adequate surgical drainage is necessary in $\mathrm{CD}$ patients with perianal abscess [123]. There is usually concern about undetected sepsis, therefore examination under anesthesia is recommended.

51. Metronidazole $400 \mathrm{mg}$ TDS or ciprofloxacin $500 \mathrm{mg}$ BD may be appropriate treatment for patients with simple symptomatic perianal fistulae

Voting: A68, B32

Level of evidence: II-2

Grade of recommendation: B

Antibiotics are an adjunctive treatment for perianal fistulae. For certain types of simple fistulae which are symptomatic, antibiotics alone may sometimes provide relief of symptoms and convert them to asymptomatic simple fistulae. In perianal
CD fistula, three trials evaluating 123 patients used either ciprofloxacin or metronidazole and showed a statistically significant effect in reducing fistula drainage $(R R=0.8 ; 95 \%$ $\mathrm{CI}=0.66-0.98)$ with no heterogeneity and an NNT of 5 (95\% CI=3-20) [126].

52. Before starting infliximab or potent immunosuppression, patients should be screened for hepatitis B virus infection, hepatitis $\mathrm{C}$ virus infection, human immunodeficiency virus infection, and tuberculosis

Voting: A68, B26, C6

Level of evidence: II-2

Grade of recommendation: B

Infliximab and other monoclonal antibodies are potent immunosuppressants and activate latent viral and mycobacterial infections, among others. It is therefore widely recommended that patients with $\mathrm{CD}$ who are planned for long-term immunosuppressive therapy should be screened for hepatitis $\mathrm{B}$ virus infection, hepatitis $\mathrm{C}$ virus infection, human immunodeficiency virus infection, and tuberculosis [127]. Ideally, it is necessary also to have these patients immunized against a variety of common infections prior to instituting immunosuppressive therapy if this is practicable [128].

53. Osteoporosis is a matter of concern in patients with $C D$ and in those on steroid therapy and should be combated by giving calcium and vitamin $\mathrm{D}$ supplements

Voting: A60, B40

Level of evidence: II-2

Grade of recommendation: B

$\mathrm{CD}$ is associated with an increased risk of osteoporosis $[129,130]$. CD, rather than UC, is associated independently with an increased risk of osteoporosis [131, 132]. Low body mass index, early disease onset, high corticosteroid doses and, anti-tumor necrosis factor $\alpha$ therapy are associated with osteoporosis in CD [130]. There are only a few small clinical trials of therapy for osteoporosis in $\mathrm{CD}$, and the general recommendation is to give calcium and vitamin $\mathrm{D}$ supplements. The only available Indian study on osteoporosis in these patients suggests that mean calcium intake is well below $200 \mathrm{mg}$ /day in these patients [129], reinforcing the need to supplement calcium. However, a recent meta-analysis suggests that bisphosphonates is effective and well tolerated in CD and reduces the risk of vertebral fractures [133].

54. There is currently no evidence to recommend use of probiotics in patients with $\mathrm{CD}$

Voting: A94, B6

Level of evidence: I

Grade of recommendation: A 
Probiotics have been used in inflammatory bowel disease by virtue of their ability in experimental systems to modulate intestinal inflammation. Two meta-analyses of clinical trials of probiotics in $\mathrm{CD}$ have concluded that there is no proven benefit, as yet, of probiotics in patients with CD [134, 135].

55. At present, there is no convincing evidence to recommend anti-Mycobacterium avium paratuberculosis therapy for patients with $\mathrm{CD}$

Voting: A100

Level of evidence: I

Grade of recommendation: A

M. avium subsp. paratuberculosis (MAP) is a cause of a granulomatous bowel disease in cattle. It has been isolated from $\mathrm{CD}$ tissues and therefore it has been suggested that it may be a cause of CD in man [136-138]. A multicenter study in Australia randomized $213 \mathrm{CD}$ patients to treatment aimed at $M A P$ using clarithromycin $750 \mathrm{mg} /$ day, rifabutin $450 \mathrm{mg} /$ day, and clofazimine $50 \mathrm{mg} /$ day or to placebo [139]. The antibiotic arm showed significantly more subjects (66\%) in remission at 16 weeks than the placebo arm ( $50 \% ; p=.02)$. Of 122 subjects entering the maintenance phase, $39 \%$ and $26 \%$ of patients taking antibiotics experienced at least 1 relapse during the first and second year, respectively, compared with $56 \%$ and $43 \%$ of patients taking placebo ( $p=.054$ and 0.14$)$. During the following year, $59 \%$ of the antibiotic group and $50 \%$ of the placebo group relapsed $(p=.54)$. The results of the abovementioned study did not support recommendation of anti-MAP therapy in patients with CD.

56. Women with CD planning pregnancy should do so during remission since active disease poses a risk to the fetus with preterm delivery and low birth weight

Voting: A88, B12

Level of evidence: II

Grade of recommendation: A

A 12-country European study including 92 pregnant women with $\mathrm{CD}$ concluded that pregnant women with $\mathrm{CD}$ had a similar disease course both during pregnancy and after delivery as did non-pregnant women with CD [140]. On the other hand, in a US nationwide sample, pregnant women with CD had higher rates of intestinal-genitourinary fistulas ( $23.4 \% \mathrm{vs}$. $3.0 \%$ ), anorectal suppuration ( $21.1 \%$ vs. $4.1 \%$ ), and overall surgical disease (59.6\% vs. $39.2 \%$ ) in comparison to nonpregnant patients with CD [141]. Preterm delivery and low birth weight was common in the CD cohort compared to pregnant women without CD. In a Swedish cohort of 1,220 births in women with $\mathrm{CD}$, an increased risk of adverse birth outcomes, such as stillbirth, growth restriction, and preterm birth, were noted particularly in those who suffered from flares throughout pregnancy [142].
57. Mesalazine and sulfasalazine can be used safely in pregnant women with $\mathrm{CD}$

Voting: A94, B6

Level of evidence: II-2

Grade of recommendation: B

In a study using medical records of patients in the UK, the risk of a major congenital anomaly in 1,703 children of mothers with IBD and 384,811 children of mothers without IBD was identical (2.7 \% and $2.8 \%$, respectively) [143]. In children of women with IBD, the adjusted odds ratio of a major congenital anomaly being associated with aminosalicylate use was 0.82 (95\% CI $0.42-1.61)$. These drugs can thus be used safely in pregnant women.

58. Corticosteroids can be used to control flares of the disease during pregnancy

Voting: A71, B23, C6

Level of evidence: II-2

Grade of recommendation: B

Corticosteroids can generally be used safely in pregnant women with $\mathrm{CD}$ [31]. A marginally increased risk (OR 3.0, $95 \%$ CI 1.08-8.54) of oral cleft malformations has been shown in a meta-analysis after exposure to corticosteroids during pregnancy. Preterm birth has also been described. Corticosteroids may therefore be used with relative safety during pregnancy, but their use may be restricted to flares during pregnancy [31].

59. Patients who were stable on azathioprine prior to pregnancy may continue the medication with little risk to the fetus

Voting: A77, B17, C6

Level of evidence: II-2

Grade of recommendation: B

Several studies of thiopurine use in pregnant women have reported normal deliveries and no excess rates of prematurity, spontaneous abortion, congenital abnormalities, or neonatal/ childhood infections in this population [31]. A recent metaanalysis concluded that thiopurine exposure in women with IBD was not associated with low birth weight or congenital abnormalities, but was associated with preterm birth [144]. However, another meta-analysis concluded that congenital abnormalities were increased significantly in thiopurine-exposed women in comparison with a control group who did not receive any medicine for IBD treatment [145]. It is generally recommended that women of reproductive age who are being commenced on azathioprine treatment for CD should be advised not to conceive during the first year of treatment. Once they are stable on treatment, they may conceive and go through pregnancy without significantly increased risk of adverse fetal outcomes. 
60. Pregnant women with $\mathrm{CD}$ with significant active perianal disease should be recommended elective cesarean section for delivery of the baby

Voting: A83, B6, C11

Level of evidence: III

Grade of recommendation: $\mathrm{C}$

Elective cesarean section is recommended in patients with perineal disease or rectal involvement [31]. It is reasonable to allow vaginal delivery for women with quiescent or mild disease and in patients with a colostomy, ileostomy, or continent ileostomy. However, if there is any obstetric indication, there should be a low threshold for making the decision in favor of a Cesarean section.

61. Iron-deficiency anemia in CD may require treatment with parenteral replacement using iron sucrose or ferric carboxymaltose

Voting: A77, B17, C6

Level of evidence: II-2

Grade of recommendation: B

Anemia occurs in CD for many reasons of which the most common is iron deficiency due to increased fecal blood losses. Oral iron supplementation is indicated in these patients [146]. Many patients do not tolerate oral iron possibly because of increased intestinal inflammation secondary to iron-dependent lipid peroxidation. In these patients, ferric carboxymaltose or iron sucrose given parenterally are good alternatives to oral iron; they are well tolerated and rapidly increase hemoglobin levels $[147,148]$. Oral iron-maltol has recently been developed as an alternative to parenteral iron preparations [149], but remains to be tested and compared against the parenteral preparations for efficacy and effectiveness.

Acknowledgement We acknowledge and deeply appreciate the support of Sun Pharmaceuticals, India who provided an unrestricted educational grant to the Indian Society of Gastroenterology for this Task Force activity.

Conflict of interest BSR, GKM, VA, UCG, VJ, BP, PA, DKB, SJB, GC, SD, DD, BDG, SKI, AKJ, RK, GL, SPM, CGP, SP, MP, AP, ASP, GR, SPS, AS, and VS confirm that they have no conflict of interest to declare.

Funding source Unrestricted educational grant from Sun Pharmaceuticals, India.

\section{References}

1. Ramakrishna BS, Makharia GK, Abraham P, et al. Indian Society of Gastroenterology consensus on ulcerative colitis. Indian J Gastroenterol. 2012;31:307-23.
2. Linstone H, Turoff M. The Delphi method: techniques and application. http://www.is.njit.edu/pubs/delphibook/. Accessed on 15 Aug 2012.

3. Periodic Health examination: 2. 1984 update. Canadian Task Force on the Periodic Health Examination. Can Med Assoc J. 1984;130: $1278-85$.

4. Tandon HD, Prakash A. Pathology of intestinal tuberculosis and its distinction from Crohn's disease. Gut. 1972;13:260-9.

5. Das SK, Montgomery RD. Chronic inflammatory bowel disease in Asian immigrants. Practitioner. 1978;221:747-9.

6. Walker AR, Segal I. Epidemiology of noninfective intestinal diseases in various ethnic groups in South Africa. Isr J Med Sci. 1979;15:309-13.

7. Bartholomew C, Butler A. Inflammatory bowel disease in the West Indies. Br Med J. 1979;2:824-5.

8. Probert CS, Jayanthi V, Hughes AO, Thompson JR, Wicks AC, Mayberry JF. Prevalence and family risk of ulcerative colitis and Crohn's disease: an epidemiological study among Europeans and south Asians in Leicestershire. Gut. 1993;34:1547-51.

9. Jayanthi V, Probert CS, Pinder D, Wicks AC, Mayberry JF. Epidemiology of Crohn's disease in Indian migrants and the indigenous population in Leicestershire. Q J Med. 1992;82:125-38.

10. Probert CS, Jayanthi V, Pollock DJ, Baithun SI, Mayberry JF, Rampton DS. Crohn's disease in Bangladeshis and Europeans in Britain: an epidemiological comparison in Tower Hamlets. Postgrad Med J. 1992;68:914-20.

11. Montgomery SM, Morris DL, Pounder RE, Wakefield AJ. Asian ethnic origin and the risk of inflammatory bowel disease. Eur $\mathbf{J}$ Gastroenterol Hepatol. 1999;11:543-6.

12. Pinsk V, Lemberg DA, Grewal K, Barker CC, Schreiber RA, Jacobson K. Inflammatory bowel disease in the South Asian pediatric population of British Columbia. Am J Gastroenterol. 2007; 102:1077-83.

13. Fellows IW, Freeman JG, Holmes GK. Crohn's disease in the city of Derby, 1951-1985. Gut. 1990;31:1262-5.

14. Veloso FT. Extraintestinal manifestations of inflammatory bowel disease: do they influence treatment and outcome? World J Gastroenterol. 2011;17:2702-7.

15. Danda D, Kurian G, Chacko A, et al. Crohn's disease in rheumatology clinic — an Indian experience. J Postgrad Med. 2005;51:26972.

16. Pugazhendhi S, Sahu MK, Subramanian V, Pulimood A, Ramakrishna BS. Environmental factors associated with Crohn's disease in India. Indian J Gastroenterol. 2011;30:264-9.

17. Goel A, Dutta AK, Pulimood AB, Eapen A, Chacko A. Clinical profile and predictors of disease behavior and surgery in Indian patients with Crohn's disease. Indian J Gastroenterol. 2013;32: 184-9.

18. Makharia GK, Ramakrishna BS, Abraham P, et al. Survey of inflammatory bowel diseases in India. Indian $\mathrm{J}$ Gastroenterol. 2012:31:299-306

19. Baskaran K, Pugazhendhi S, Ramakrishna BS. Association of IRGM gene mutations with inflammatory bowel disease in the Indian population. PLoS One. 2014;9:e106863.

20. Das K, Ghoshal UC, Dhali GK, Benjamin J, Ahuja V, Makharia GK. Crohn's disease in India: a multicenter study from a country where tuberculosis is endemic. Dig Dis Sci. 2009;54:1099-107.

21. Pai CG, Khandige GK. Is Crohn's disease rare in India? Indian J Gastroenterol. 2000;19:17-20.

22. Amarapurkar DN, Patel ND, Rane PS. Diagnosis of Crohn's disease in India where tuberculosis is widely prevalent. World J Gastroenterol. 2008;14:741-6.

23. Cho JH, Abraham C. Inflammatory bowel disease genetics: Nod2. Annu Rev Med. 2007;58:401-16. 
24. Adler J, Rangwalla SC, Dwamena BA, Higgins PD. The prognostic power of the NOD2 genotype for complicated Crohn's disease: a meta-analysis. Am J Gastroenterol. 2011;106:699-712.

25. Juyal G, Amre D, Midha V, Sood A, Seidman E, Thelma BK. Evidence of allelic heterogeneity for associations between the NOD2/CARD15 gene and ulcerative colitis among North Indians. Aliment Pharmacol Ther. 2007;26:1325-32.

26. Pugazhendhi S, Amte A, Balamurugan R, Subramanian V, Ramakrishna BS. Common NOD2 mutations are absent in patients with Crohn's disease in India. Indian J Gastroenterol. 2008;27:201-3.

27. Mahurkar S, Banerjee R, Rani VS, et al. Common variants in NOD2 and IL23R are not associated with inflammatory bowel disease in Indians. J Gastroenterol Hepatol. 2011;26:694-9.

28. Lennard-Jones JE. Classification of inflammatory bowel disease. Scand J Gastroenterol Suppl. 1989;170:2-6.

29. Pulimood AB, Ramakrishna BS, Kurian G, Mathan VI, Mathan M. Endoscopic mucosal biopsies are useful in distinguishing granulomatous colitis due to Crohn's disease from tuberculosis. Gut. 1999;45:537-41.

30. Pulimood A, Peter S, Ramakrishna BS, Kurian G. Segmental colonoscopic biopsies in the differentiation of ileocolic tuberculosis from Crohn's disease. J Gastroenterol Hepatol. 2005;20:688-96.

31. Van Assche G, Dignass A, Reinisch W, et al. The second European evidence-based consensus on the diagnosis and management of Crohn's disease: special situations. J Crohn's Colitis. 2010;4:63-101.

32. Ramadass B, Chittaranjan S, Subramanian V, Ramakrishna BS. Fecal polymerase chain reaction for Mycobacterium tuberculosis IS6110 to distinguish Crohn's disease from intestinal tuberculosis. Indian J Gastroenterol. 2010;29:152-6.

33. Makharia GK, Srivastava S, Das P, et al. Clinical, endoscopic, and histological differentiations between Crohn's disease and intestinal tuberculosis. Am J Gastroenterol. 2010;105:642-51.

34. Dutta AK, Sahu MK, Gangadharan SK, Chacko A. Distinguishing Crohn's disease from intestinal tuberculosis - a prospective study. Trop Gastroenterol. 2011;32:204-9.

35. Pulimood AB, Amarapurkar DN, Ghoshal U, et al. Differentiation of Crohn's disease from intestinal tuberculosis in India in 2010. World J Gastroenterol. 2011;17:433-43.

36. Tony J, Sunilkumar K, Thomas V. Randomized controlled trial of DOTS versus conventional regime for treatment of ileocecal and colonic tuberculosis. Indian J Gastroenterol. 2008;27:19-21.

37. Makharia GK, Agnihotri A, Ghoshal UC, et al. A comparison between efficacy of 6 months versus 9 months of intermittent antituberculous therapy for abdominal tuberculosis (intestinal and peritoneal): a randomized controlled trial. Indian J Gastroenterol. 2014;33 Suppl 1:A18.

38. Nienhaus A, Schablon A, Diel R. Interferon-gamma release assay for the diagnosis of latent TB infection - analysis of discordant results, when compared to the tuberculin skin test. PLoS One. 2008;3:e2665.

39. Lee JN, Ryu DY, Park SH, et al. The usefulness of in vitro interferongamma assay for differential diagnosis between intestinal tuberculosis and Crohn's disease. Korean J Gastroenterol. 2010;55:376-83.

40. Kim YS, Kim YH, Kim WH, et al. Diagnostic utility of antiSaccharomyces cerevisiae antibody (ASCA) and Interferon- $\gamma$ assay in the differential diagnosis of Crohn's disease and intestinal tuberculosis. Clin Chim Acta. 2011;412:1527-32.

41. Prideaux L, De Cruz P, Ng SC, Kamm MA. Serological antibodies in inflammatory bowel disease: a systematic review. Inflamm Bowel Dis. 2012;18:1340-55.

42. Ghoshal UC, Ghoshal U, Singh H, Tiwari S. Anti-Saccharomyces cerevisiae antibody is not useful to differentiate between Crohn's disease and intestinal tuberculosis in India. J Postgrad Med. 2007;53:166-70.
43. Makharia GK, Sachdev V, Gupta R, Lal S, Pandey RM. AntiSaccharomyces cerevisiae antibody does not differentiate between Crohn's disease and intestinal tuberculosis. Dig Dis Sci. 2007;52:33-9.

44. Kim KM, Lee A, Choi KY, Lee KY, Kwak JJ. Intestinal tuberculosis: clinicopathologic analysis and diagnosis by endoscopic biopsy. Am J Gastroenterol. 1998;93:606-9.

45. Gan HT, Chen YQ, Ouyang Q, Bu H, Yang XY. Differentiation between intestinal tuberculosis and Crohn's disease in endoscopic biopsy specimens by polymerase chain reaction. Am J Gastroenterol. 2002;97:1446-51.

46. Amarapurkar DN, Patel ND, Amarapurkar AD, Agal S, Baigal R, Gupte P. Tissue polymerase chain reaction in diagnosis of intestinal tuberculosis and Crohn's disease. J Assoc Physicians India. 2004;52:863-7.

47. Pulimood AB, Peter S, Rook GW, Donoghue HD. In situ PCR for Mycobacterium tuberculosis in endoscopic mucosal biopsy specimens of intestinal tuberculosis and Crohn's disease. Am J Clin Pathol. 2008;129:846-51.

48. Silverberg MS, Satsangi J, Ahmad T, et al. Toward an integrated clinical, molecular and serological classification of inflammatory bowel disease: report of a working party of the 2005 Montreal world congress of gastroenterology. Can J Gastroenterol. 2005;19 Suppl A:5A-36A.

49. Van Assche G, Dignass A, Panes J, et al. The second European evidence-based consensus on the diagnosis and management of Crohn's disease: definitions and diagnosis. J Crohns Colitis. 2010;4:7-27.

50. Annunziata ML, Caviglia R, Papparella LG, Cicala M. Upper gastrointestinal involvement of Crohn's disease: a prospective study on the role of upper endoscopy in the diagnostic work-up. Dig Dis Sci. 2012;57:1618-23

51. Hummel TZ, ten Kate FJ, Reitsma JB, Benninga MA, Kindermann A. Additional value of upper GI tract endoscopy in the diagnostic assessment of childhood IBD. J Pediatr Gastroenterol Nutr. 2012;54:753-7.

52. Jin XJ, Kim JM, Kim HK, et al. Histopathology and TB-PCR kit analysis in differentiating the diagnosis of intestinal tuberculosis and Crohn's disease. World J Gastroenterol. 2010;16:2496-503.

53. Triester SL, Leighton JA, Leontiadis GI, et al. A meta-analysis of the yield of capsule endoscopy compared to other diagnostic modalities in patients with non-stricturing small bowel Crohn's disease. Am J Gastroenterol. 2006;101:954-64.

54. Pasha SF, Leighton JA, Das A, et al. Double-balloon enteroscopy and capsule endoscopy have comparable diagnostic yield in small-bowel disease: a meta-analysis. Clin Gastroenterol Hepatol. 2008;6:671-6.

55. Baumgart DC, Sandborn WJ. Inflammatory bowel disease: clinical aspects and established and evolving therapies. Lancet. 2007;369: 1641-57.

56. Yao T, Matsui T, Hiwatashi N. Crohn's disease in Japan: diagnostic criteria and epidemiology. Dis Colon Rectum. 2000;43 10 Suppl: S85-93.

57. Sandborn WJ, Feagan BG, Hanauer SB, et al. A review of activity indices and efficacy endpoints for clinical trials of medical therapy in adults with Crohn's disease. Gastroenterology. 2002;122:512-30.

58. Vermeire S, Schreiber S, Sandborn WJ, Dubois C, Rutgeerts P. Correlation between the Crohn's disease activity and HarveyBradshaw indices in assessing Crohn's disease severity. Clin Gastroenterol Hepatol. 2010;8:357-63.

59. Walters TD, Steinhart AH, Bernstein CN, et al. Validating Crohn's disease activity indices for use in assessing postoperative recurrence. Inflamm Bowel Dis. 2011;17:1547-56.

60. Korelitz BI, Sommers SC. Response to drug therapy in Crohn's disease: evaluation by rectal biopsy and mucosal cell counts. J Clin Gastroenterol. 1984;6:123-7.

61. D'Haens G, Geboes K, Ponette E, Penninckx F, Rutgeerts P. Healing of severe recurrent ileitis with azathioprine therapy in patients with Crohn's disease. Gastroenterology. 1997;112:1475-81. 
62. Mandel MD, Miheller P, Müllner K, Golovics PA, Lakatos PL. Have biologics changed the natural history of Crohn's disease? Dig Dis. 2014;32:351-9.

63. Reinisch W, Colombel JF, Sandborn WJ, et al. Factors associated with short- and long-term outcomes of therapy for Crohn's disease. Clin Gastroenterol Hepatol. 2015; 13:539-47.

64. Dai C, Liu WX, Jiang M, Sun MJ. Mucosal healing did not predict sustained clinical remission in patients with IBD after discontinuation of one-year infliximab therapy. PLoS One. 2014;9:e110797.

65. Bodger K, Kikuchi T, Hughes D. Cost-effectiveness of biological therapy for Crohn's disease: Markov cohort analyses incorporating United Kingdom patient-level cost data. Aliment Pharmacol Ther. 2009;30:265-74.

66. Tang DH, Armstrong EP, Lee JK. Cost-utility analysis of biologic treatments for moderate-to-severe Crohn's disease. Pharmacotherapy. 2012;32:515-26.

67. Lim WC, Hanauer S. Aminosalicylates for induction of remission or response in Crohn's disease. Cochrane Database Syst Rev. 2010;12: CD008870.

68. Ford AC, Kane SV, Khan KJ, et al. Efficacy of 5-aminosalicylates in Crohn's disease: systematic review and meta-analysis. Am J Gastroenterol. 2011;106:617-29.

69. Gearry RB, Ajlouni Y, Nandurkar S, Iser JH, Gibson PR. 5Aminosalicylic acid (mesalazine) use in Crohn's disease: a survey of the opinions and practice of Australian gastroenterologists. Inflamm Bowel Dis. 2007;13:1009-15.

70. Sung JJ, Kamm MA, Marteau P. Asian perspectives in the management of inflammatory bowel disease: findings from a recent survey. J Gastroenterol Hepatol. 2010;25:183-93.

71. Duricova D, Pedersen N, Elkjaer M, Jensen JK, Munkholm P. 5aminosalicylic acid dependency in Crohn's disease: a Danish Crohn colitis database study. J Crohns Colitis. 2010;4:575-81.

72. Talley NJ, Abreu MT, Achkar JP, et al. An evidence-based systematic review on medical therapies for inflammatory bowel disease. Am J Gastroenterol. 2011;106 Suppl 1:S2-25.

73. McKeage K, Goa KL. Budesonide (Entocort EC Capsules): a review of its therapeutic use in the management of active Crohn's disease in adults. Drugs. 2002;62:2263-82.

74. Tremaine WJ, Hanauer SB, Katz S, et al. Budesonide CIR capsules (once or twice daily divided-dose) in active Crohn's disease: a randomized placebo-controlled study in the United States. Am J Gastroenterol. 2002;97:1748-54.

75. Bar-Meir S, Chowers Y, Lavy A, et al. Budesonide versus prednisone in the treatment of active Crohn's disease. The Israeli budesonide study group. Gastroenterology. 1998;115:835-40.

76. Ford AC, Bernstein CN, Khan KJ, et al. Glucocorticosteroid therapy in inflammatory bowel disease: systematic review and meta-analysis. Am J Gastroenterol. 2011;106:590-9.

77. Dignass A, Van Assche G, Lindsay JO, et al. The second European evidence-based consensus on the diagnosis and management of Crohn's disease: current management. J Crohns Colitis. 2010;4:28-62.

78. Summers RW, Switz DM, Sessions JT Jr, et al. National cooperative Crohn's disease study: results of drug treatment. Gastroenterology. 1979;77:847-69.

79. Malchow H, Ewe K, Brandes JW, et al. European cooperative Crohn's disease study (ECCDS): results of drug treatment. Gastroenterology. 1984;86:249-66.

80. Munkholm P, Langholz E, Davidsen M, Binder V. Frequency of glucocorticoid resistance and dependency in Crohn's disease. Gut. 1994;35:360-2.

81. Benchimol EI, Seow CH, Steinhart AH, Griffiths AM. Traditional corticosteroids for induction of remission in Crohn's disease. Cochrane Database Syst Rev. 2008;2:CD006792.

82. McDonald JW, Wang Y, Tsoulis DJ, MacDonald JK, Feagan BG. Methotrexate for induction of remission in refractory Crohn's disease. Cochrane Database Syst Rev. 2014;8:CD003459.
83. Prefontaine E, Macdonald JK, Sutherland LR. Azathioprine or 6mercaptopurine for induction of remission in Crohn's disease. Cochrane Database Syst Rev. 2010;6:CD000545.

84. Chande N, Tsoulis DJ, MacDonald JK. Azathioprine or 6mercaptopurine for induction of remission in Crohn's disease. Cochrane Database Syst Rev. 2013;4:CD000545.

85. Benjamin J, Makharia GK, Kalaivani M, Joshi YK. Nutritional status of patients with Crohn's disease. Indian J Gastroenterol. 2008;27:195-200.

86. Benjamin J, Makharia G, Ahuja V, Joshi YK. Body composition in Indian patients with Crohn's disease during active and remission phase. Trop Gastroenterol. 2011;32:285-91.

87. Shamir R. Nutrition and growth in inflammatory bowel disease. World Rev Nutr Diet. 2013;106:156-61.

88. Massironi S, Rossi RE, Cavalcoli FA, Della Valle S, Fraquelli M, Conte D. Nutritional deficiencies in inflammatory bowel disease: therapeutic approaches. Clin Nutr. 2013;32:904-10.

89. Bermejo F, Garrido E, Chaparro M, et al. Efficacy of different therapeutic options for spontaneous abdominal abscesses in Crohn's disease: are antibiotics enough? Inflamm Bowel Dis. 2012;18: 1509-14.

90. de Groof EJ, Carbonnel F, Buskens CJ, Bemelman WA. Abdominal abscess in Crohn's disease: multidisciplinary management. Dig Dis. 2014;32 Suppl 1:103-9.

91. Lobatón T, Guardiola J, Rodriguez-Moranta F, et al. Comparison of the long-term outcome of two therapeutic strategies for the management of abdominal abscess complicating Crohn's disease: percutaneous drainage or immediate surgical treatment. Colorectal Dis. 2013;15:1267-72.

92. van Deen WK, van Oijen MG, Myers KD, et al. A nationwide 2010-2012 analysis of U.S. health care utilization in inflammatory bowel diseases. Inflamm Bowel Dis. 2014;20:1747-53.

93. Schoepfer AM, Bortolotti M, Pittet V, et al. The gap between scientific evidence and clinical practice: 5-aminosalicylates are frequently used for the treatment of Crohn's disease. Aliment Pharmacol Ther. 2014;40:930-7.

94. Khan KJ, Dubinsky MC, Ford AC, Ullman TA, Talley NJ, Moayyedi P. Efficacy of immunosuppressive therapy for inflammatory bowel disease: a systematic review and meta-analysis. Am J Gastroenterol. 2011;106:630-42.

95. Prefontaine E, Sutherland LR, Macdonald JK, Cepoiu M. Azathioprine or 6-mercaptopurine for maintenance of remission in Crohn's disease. Cochrane Database Syst Rev. 2009;1:CD000067.

96. Kuenzig ME, Rezaie A, Seow CH, et al. Budesonide for maintenance of remission in Crohn's disease. Cochrane Database Syst Rev. 2014;8:CD002913.

97. French H, Mark Dalzell A, Srinivasan R, El-Matary W. Relapse rate following azathioprine withdrawal in maintaining remission for Crohn's disease: a meta-analysis. Dig Dis Sci. 2011;56:1929-36.

98. Freeman HJ. Natural history and long-term clinical course of Crohn's disease. World J Gastroenterol. 2014;20:31-6.

99. Golovics PA, Mandel MD, Lovasz BD, Lakatos PL. Inflammatory bowel disease course in Crohn's disease: is the natural history changing? World J Gastroenterol. 2014;20:3198-207.

100. http://www.bsg.org.uk/pdf_word_docs/aza_ibd_dr.doc. Accessed on 4th January 2015.

101. Gearry RB, Barclay ML. Azathioprine and 6-mercaptopurine pharmacogenetics and metabolite monitoring in inflammatory bowel disease. J Gastroenterol Hepatol. 2005;20:1149-57.

102. Anstey AV, Wakelin S, Reynolds NJ. British association of dermatologists therapy, guidelines and audit subcommittee. Guidelines for prescribing azathioprine in dermatology. Br J Dermatol. 2004;151: 1123-32.

103. http://www.nlm.nih.gov/medlineplus/druginfo/meds/a682167.html. Accessed on 4th January 2015. 
104. Ford AC, Sandborn WJ, Khan KJ, Hanauer SB, Talley NJ, Moayyedi P. Efficacy of biological therapies in inflammatory bowel disease: systematic review and meta-analysis. Am J Gastroenterol. 2011;106:644-59.

105. Kawalec P, Mikrut A, Wiśniewska N, Pilc A. Tumor necrosis factor$\alpha$ antibodies (infliximab, adalimumab and certolizumab) in Crohn's disease: systematic review and meta-analysis. Arch Med Sci. 2013;9:765-79.

106. Stidham RW, Lee TC, Higgins PD, et al. Systematic review with network meta-analysis: the efficacy of anti-TNF agents for the treatment of Crohn's disease. Aliment Pharmacol Ther. 2014;39:134962.

107. Peyrin-Biroulet L, Deltenre P, de Suray N, Branche J, Sandborn WJ, Colombel JF. Efficacy and safety of tumor necrosis factor antagonists in Crohn's disease: meta-analysis of placebo-controlled trials. Clin Gastroenterol Hepatol. 2008;6:644-53.

108. Amiot A, Setakhr V, Seksik P, et al. Long-term outcome of enterocutaneous fistula in patients with Crohn's disease treated with anti-TNF therapy: a cohort study from the GETAID. Am J Gastroenterol. 2014;109:1443-9.

109. Bouguen G, Siproudhis L, Gizard E, et al. Long-term outcome of perianal fistulizing Crohn's disease treated with infliximab. Clin Gastroenterol Hepatol. 2013;11:975-81.

110. Prevention Committee of the Japanese Society for Tuberculosis, Treatment Committee of the Japanese Society for Tuberculosis. Treatment guidelines for latent tuberculosis infection. Kekkaku. 2014;89:21-37.

111. Chen $\mathrm{CH}$, Shu $\mathrm{KH}, \mathrm{Ho} \mathrm{HC}$, et al. A nationwide population-based study of the risk of tuberculosis in different solid organ transplantations in Taiwan. Transplant Proc. 2014;46:1032-5.

112. Hadaya K, Bridevaux PO, Roux-Lombard P, et al. Contribution of interferon- $\gamma$ release assays (IGRAs) to the diagnosis of latent tuberculosis infection after renal transplantation. Transplantation. 2013;95:1485-90.

113. Ferguson TW, Tangri N, Macdonald K, et al. The diagnostic accuracy of tests for latent tuberculosis infection in hemodialysis patients: a systematic review and meta-analysis. Transplantation. 2014 Oct 3.

114. Cristaldi M, Sampietro GM, Danelli PG, Bollani S, Bianchi Porro G, Taschieri AM. Long-term results and multivariate analysis of prognostic factors in 138 consecutive patients operated on for Crohn's disease using "bowel-sparing" techniques. Am J Surg. 2000;179:266-70.

115. Mortara G, Ghirardi M, Prati M, et al. Surgical treatment of inflammatory bowel diseases in northwestern Italy: a multicentric study by the G.S.M.I.I. (inflammatory bowel disease study group). Ann Ital Chir. 2003;74:319-26.

116. Walker DG, Williams HR, Kane SP, et al. Differences in inflammatory bowel disease phenotype between South Asians and Northern Europeans living in North West London, UK. Am J Gastroenterol. 2011;106:1281-9.

117. Prakash K, Varma D, Mahadevan P, Narayanan RG, Philip M. Surgical treatment for small bowel Crohn's disease: an experience of 28 cases. Indian J Gastroenterol. 2008;27:12-5.

118. Forbes A. Crohn's disease: rehabilitation after resection. Dig Dis. 2014;32:395-8.

119. Hesham W, Kann BR. Strictureplasty. Clin Colon Rectal Surg. 2013;26:80-3.

120. Erkelens GW, van Deventer SJ. Endoscopic treatment of strictures in Crohn's disease. Best Pract Res Clin Gastroenterol. 2004;18:2017.

121. Hassan C, Zullo A, De Francesco V, et al. Systematic review: endoscopic dilatation in Crohn's disease. Aliment Pharmacol Ther. 2007;26:1457-64

122. Gustavsson A, Magnuson A, Blomberg B, Andersson M, Halfvarson J, Tysk C. Endoscopic dilation is an efficacious and safe treatment of intestinal strictures in Crohn's disease. Aliment Pharmacol Ther. 2012;36:151-8.

123. Gecse KB, Bemelman W, Kamm MA, et al. A global consensus on the classification, diagnosis and multidisciplinary treatment of perianal fistulising Crohn's disease. Gut. 2014;63:1381-92.

124. Sordo-Mejia R, Gaertner WB. Multidisciplinary and evidencebased management of fistulizing perianal Crohn's disease. World J Gastrointest Pathophysiol. 2014;5:239-51.

125. Yassin NA, Askari A, Warusavitarne J, et al. Systematic review: the combined surgical and medical treatment of fistulising perianal Crohn's disease. Aliment Pharmacol Ther. 2014;40:741-9.

126. Khan KJ, Ullman TA, Ford AC, et al. Antibiotic therapy in inflammatory bowel disease: a systematic review and meta-analysis. Am J Gastroenterol. 2011;106:661-73.

127. Chebli JM, Gaburri PD, Chebli LA, et al. A guide to prepare patients with inflammatory bowel diseases for anti-TNF- $\alpha$ therapy. Med Sci Monit. 2014;20:487-98.

128. Campins M, Cossio Y, Martínez X, Borruel N. Vaccination of patients with inflammatory bowel disease. Practical recommendations. Rev Esp Enferm Dig. 2013;105:93-102.

129. Khadgawat R, Makharia GK, Puri K. Evaluation of bone mineral density among patients with inflammatory bowel disease in a tertiary care setting in India. Indian J Gastroenterol. 2008;27:103-6.

130. Azzopardi N, Ellul P. Risk factors for osteoporosis in Crohn's disease: infliximab, corticosteroids, body mass index, and age of onset. Inflamm Bowel Dis. 2013;19:1173-8.

131. Targownik LE, Bernstein CN, Leslie WD. Risk factors and management of osteoporosis in inflammatory bowel disease. Curr Opin Gastroenterol. 2014;30:168-74.

132. Tsai MS, Lin CL, Tu YK, Lee PH, Kao CH. Risks and predictors of osteoporosis in patients with inflammatory bowel diseases in an Asian population: a nationwide population-based cohort study. Int J Clin Pract. 2015;69:235-41.

133. Melek J, Sakuraba A. Efficacy and safety of medical therapy for low bone mineral density in patients with inflammatory bowel disease: a meta-analysis and systematic review. Clin Gastroenterol Hepatol. 2014; 12:32-44.

134. Jonkers D, Penders J, Masclee A, Pierik M. Probiotics in the management of inflammatory bowel disease: a systematic review of intervention studies in adult patients. Drugs. 2012;72:803-23.

135. Ghouri YA, Richards DM, Rahimi EF, Krill JT, Jelinek KA, DuPont AW. Systematic review of randomized controlled trials of probiotics, prebiotics, and synbiotics in inflammatory bowel disease. Clin Exp Gastroenterol. 2014;7:473-87.

136. Rosenfeld G, Bressler B. Mycobacterium avium paratuberculosis and the etiology of Crohn's disease: a review of the controversy from the clinician's perspective. Can J Gastroenterol. 2010;24: 619-24.

137. Singh AV, Singh SV, Singh PK, Sohal JS. Is Mycobacterium avium subsp. paratuberculosis, the cause of Johne's disease in animals, a good candidate for Crohn's disease in man? Indian J Gastroenterol. 2010;29:53-8

138. Liverani E, Scaioli E, Cardamone C, Dal Monte P, Belluzzi A. Mycobacterium avium subspecies paratuberculosis in the etiology of Crohn's disease, cause or epiphenomenon? World J Gastroenterol. 2014;20:13060-70.

139. Selby W, Pavli P, Crotty B, et al. Two-year combination antibiotic therapy with clarithromycin, rifabutin, and clofazimine for Crohn's disease. Gastroenterology. 2007;132:2313-9.

140. Pedersen N, Bortoli A, Duricova D, et al. The course of inflammatory bowel disease during pregnancy and postpartum: a prospective European ECCO-EpiCom Study of 209 pregnant women. Aliment Pharmacol Ther. 2013;38:501-12.

141. Hatch Q, Champagne BJ, Maykel JA, et al. The impact of pregnancy on surgical Crohn disease: an analysis of the Nationwide Inpatient Sample. J Surg Res. 2014;190:41-6. 
142. Bröms G, Granath F, Linder M, Stephansson O, Elmberg M, Kieler $\mathrm{H}$. Birth outcomes in women with inflammatory bowel disease: effects of disease activity and drug exposure. Inflamm Bowel Dis. 2014;20:1091-8.

143. Ban L, Tata LJ, Fiaschi L, Card T. Limited risks of major congenital anomalies in children of mothers with IBD and effects of medications. Gastroenterology. 2014;146:76-84.

144. Akbari M, Shah S, Velayos FS, Mahadevan U, Cheifetz AS. Systematic review and meta-analysis on the effects of thiopurines on birth outcomes from female and male patients with inflammatory bowel disease. Inflamm Bowel Dis. 2013;19:15-22.

145. Mozaffari S, Abdolghaffari A, Nikfar S, Abdollahi M. Pregnancy outcomes in women with inflammatory bowel disease following exposure to thiopurines and antitumor necrosis factor drugs: a systematic review with meta-analysis. Hum Exp Toxicol. 2014 Nov 5.
146. Blumenstein I, Dignass A, Vollmer S, Klemm W, Weber-Mangal S, Stein J. Current practice in the diagnosis and management of IBDassociated anaemia and iron deficiency in Germany: the German AnaemIBD Study. J Crohns Colitis. 2014;8:1308-14.

147. Laass MW, Straub S, Chainey S, Virgin G, Cushway T. Effectiveness and safety of ferric carboxymaltose treatment in children and adolescents with inflammatory bowel disease and other gastrointestinal diseases. BMC Gastroenterol. 2014;14:184.

148. Dignass AU, Gasche C, Bettenworth D, et al. European consensus on the diagnosis and management of iron deficiency and anaemia in inflammatory bowel diseases. J Crohns Colitis. 2015;9:211-22.

149. Gasche C, Ahmad T, Tulassay Z, et al. Ferric maltol is effective in correcting iron deficiency anemia in patients with inflammatory bowel disease: results from a Phase-3 clinical trial program. Inflamm Bowel Dis. 2015;21:579-88. 